\title{
Meaningful Adoption: What We Know or Think We Know About the Financing, EFFECTIVENESS, QuALITY, AND SAFETY OF ELECTRONIC MEDICAL RECORDS
}

\author{
Nicolas P. Terry ${ }^{*}$
}

\begin{abstract}
What is clear is that electronic medical records facilitate documentation of services rendered by physicians and hospitals, which is used to justify billing. Doctors in particular are burdened with checking off scores of boxes on the computer screen to satisfy insurance requirements, so called "pay for performance." But again, there are no compelling data to demonstrate that such voluminous documentation translates into better outcomes for their sick patients. ${ }^{1}$
\end{abstract}

When doctors and hospitals use health IT, patients get better care and we save money. ... We're making great progress, but we can't wait to do more. Too many doctors and hospitals are still using the same record-keeping technology as Hippocrates. Today, we are making it easier for health care providers to use new technology to improve the health care system for all of us and create more jobs. ${ }^{2}$

\footnotetext{
* Hall Render Professor of Law \& Co-Director of the Hall Center for Law and Health, Indiana University Robert H. McKinney School of Law. I thank Efthimios Parasidis for his perceptive comments on an earlier draft. Professor Miriam Murphy helped immeasurably with research and Alex Smith assisted with timely edits. Of course, the errors are mine alone. Copyright 2012, Nicolas P. Terry. All Rights Reserved. This article is based on a presentation given at the 14th Annual SIH/SIU Health Policy Institute "EHRs, EMRs and Health Information Technology: To Meaningful Use and Beyond," May 18, 2012, Southern Illinois University School of Law. Direct correspondence to Professor Terry at npterry@iupui.edu.

'Jerome Groopman \& Pamela Hartzband, Obama's $\$ 80$ Billion Exaggeration, Wall ST. J., Mar. 12, 2009, http://online.wsj.com/article/SB123681586452302125.html.

${ }^{2}$ Press Release, U.S. Dep't of Health and Human Servs., Obama Administration Takes New Steps to Encourage Doctors and Hospitals to Use Health Information Technology to Lower Costs, Improve Quality, Create Jobs (Nov. 30, 2011), available at http://www.hhs.gov/news/press/2011 pres/11/20111130a. html.
} 


\section{INTRODUCTION}

The current state of the implementation of health information technology (HIT) and its progeny, such as the electronic medical record (EMR), is opaque. Given the amount of federal money being pumped into HIT adoption courtesy of the American Recovery and Reinvestment Act of 2009 (ARRA), it is hardly surprising that the government's HIT leaders frequently seek out a positive statistic to support their optimistic public comments about the state of the current initiative. Equally, industry stakeholders, whether they are physicians or hospitals looking to receive government meaningful use (MU) subsidies or HIT vendors filling orders for certifiable EMRs, make supportive, progressive noises.

Both before and during the course of this technological promotion, the overwhelming majority of commentators have taken the position that EMRs will solve many, if not all, of healthcare's quality and efficiency woes. ${ }^{3}$ This article takes a more critical stance. It argues that increasingly there are grounds to doubt that conventional wisdom and suggest that the impact of EMRs may be relatively minor, particularly in the short term. The article also discusses a related argument, that the current generation of EMRs may not be capable of promoting major safety or quality gains because of problems with their usability, technological limitations that impede interoperability, and concerns about their safety. Taken together these observations cast some doubt on the current market failure-subsidy model. Is it possible that the market has actually been functioning perfectly well because many providers do not see sufficient value in the current generation of the technology? If so, the exception may prove the rule, that only well-funded large systems with strong integrative skills or vertically integrated providers can effectively leverage this generation of EMR technology.

Part I tells the generally negative story of EMR adoption prior to the MU program. The MU program is described in Part II with particular emphasis given to the new Stage 2 rule. Part III pivots to a more critical and central analysis by posing the question whether the MU program has (or will) result in

\footnotetext{
${ }^{3}$ See, e.g., Barry R. Furrow, Adverse Events and Patient Injury: Coupling Detection, Disclosure, and Compensation, 46 New Eng. L. Rev. 437 (2012); Leslie Pickering Francis, The Physician-Patient Relationship and a National Health Information Network, 38 J.L. MeD. \& ETHICs 36 (2010); Laura Ashpole, Health Information Technology: Building the Foundation for the Reconstruction of Health Care Delivery, 20 Annals HeAlth L. 32 (2011); Susan R. Gering, Electronic Health Records: How to Avoid Digital Disaster, 16 Micн. ST. U.J. MED. \& L. 297 (2012); Sharona Hoffman \& Andy Podgurski, Improving Health Care Outcomes through Personalized Comparisons of Treatment Effectiveness Based on Electronic Health Records, 39 J.L. MED. \& ETHICs 425 (2011). This author is similarly guilty. See, e.g., Nicolas P. Terry, Certification and Meaningful Use: Reframing Adoption of Electronic Health Records as a Quality Imperative, 8 IND. HEALTH L. Rev. 43 (2011); Nicolas Terry, To HIPAA, a Son: Assessing the Technical, Conceptual, and Legal Frameworks for Patient Safery Information, 12 WIDENER L. Rev. 134 (2006).
} 
meaningful adoption. Part IV casts the critical net more broadly, speculating about the quality failures and safety externalities of the current generation of EMRs.

At the heart of this story are the Centers for Medicare \& Medicaid Services (CMS) and the Office of the National Coordinator for Health Information Technology (ONC). These two Health and Human Services (HHS) agencies control the subsidy program via the $\mathrm{MU}$ and certification regulations. The article concludes that the progress seen so far is somewhat pedestrian and that trajectory will continue until CMS and ONC demand more sophisticated utilization of HIT in exchange for the MU subsidy funds.

\section{HISTORY, CULTURE, MARKET FAILURE, AND SUBSIDY}

IBM had a primitive experimental computer-based records system running at Akron Children's Hospital in 1962 ${ }^{4}$ However, it was Dr. Lawrence Weed who became known as the "father of the problem-oriented medical record" through his work at the University of Vermont beginning in 1969. ${ }^{5}$ Beginning in the 1970s, the Regenstrief Institute at Indiana University School of Medicine developed an EMR system and, in 1994, the Indiana Network for Patient Care became the first major interoperable network. ${ }^{6}$ For over four decades, advances were made across many HIT fronts by a large number of talented researchers typically supported by the Agency for Healthcare Research and Quality (AHRQ) and its predecessor agencies. ${ }^{7}$

Policymakers entered the debate because of the normative claims of a 1997 Institute of Medicine (IoM) report. That report, The Computer-Based Patient Record, provided a roadmap for the future development and implementation of EMRs. ${ }^{8}$ By 2005, its financial model was moved forward by a

\footnotetext{
${ }^{4}$ Steve Lohr, The "Miracle" of Digital Health Records, 50 Years Ago, N.Y. Times, Feb. 17, 2012, http://bits.blogs.nytimes.com/2012/02/17/the-miracle-of-digital-health-records-50-years-ago/.

${ }^{5}$ Lawrence L. Weed, Medical Records That Guide and Teach, 278 NEw ENG. J. Med. 593 (1968), available at http://imed. stanford.edu/curriculum/session 17/content/NEJM \% 20-\%20Medical\% 20 record $\% 20$ that $\% 20$ guide $\% 20$ and $\% 20$ teach\% 20 (Weed $\% 20-\% 201968$ ).pdf. "It can readily be seen that all narrative data presently in the medical record can be structured, and in the future all narrative data may be entered through series of displays, guaranteeing a thoroughness, retrieveability, efficiency and economy important to the scientific analysis of a type of datum that has hitherto been handled in a very unrigorous manner." Id.

${ }^{6}$ Regenstrief Inst., Inc., INPC History, Indiana Network for Patient Care, http://www.regenstrief.org/ medinformatics/inpc/history- 1 .

${ }^{7}$ J. Michael Fitzmaurice et al., Three Decades of Research on Computer Applications in Health Care: Medical Informatics Support at the Agency for Healthcare Research and Quality, 9 J. Am. MED. INFORMATICS Ass'N 144, 144 (2002), http://www.ncbi.nlm.nih.gov/pmc/articles/PMC344572/ pdf/0090144.pdf.

${ }^{8}$ See Comm. on Improving the Patient Record Div. of Health Care Serv., Inst. Med. (Richard S. Dick et al. eds., revised ed. 2007).
} 
report from the RAND HIT project that connected broad EMR implementation to annual savings of $\$ 81$ billion from improved healthcare efficiency and safety. ${ }^{9}$ And, Crossing the Quality Chasm ${ }^{10}$ the IoM's sequel to To Err Is Human, ${ }^{11}$ contained the clear directive that, "IT must pay a central role in the redesign of the health care system if a substantial improvement in health care quality is to be achieved during the coming decade" and that "[a]utomation of clinical, financial, and administrative transactions is essential to improving quality, preventing errors, enhancing consumer confidence in the health system, and improving efficiency."12

The political history of EMRs began in 2004 when President G.W. Bush announced: "Within 10 years, we want most Americans to have electronic health care records-that means your records.... You not only save money, you improve the quality of care through the spread of good information."13 The President proceeded to set up ONC under Dr. David Brailer. Brailer and his team embarked on a two-pronged strategy, working with standards bodies and the health care industry to sort out the technical standards for information exchange and simultaneously using the power of the bully pulpit to urge providers and the HIT industry toward implementation. ${ }^{14}$

The pioneering efforts of researchers, policymakers, and government alike were wasted as the health care system persisted with paper records. Worse, paper records were interred in physician offices. This trapping of patient information in archetypal data siloes impeded continuity of care and promoted expensive multiple, duplicative tests. In parallel, retention of paper media led to errors in recording patient information and medication prescribing errors. Former House Speaker Newt Gingrich was forthright about continued use of paper, stating: "You show me a paper medical record, and I'll tell you about the 44,000 to 98,000 Americans who are killed every year by preventable medical errors. You show me a paper prescription, and I'll tell you about the more than 7,000 Americans who die every year from unnecessary medication errors." 15

\footnotetext{
${ }^{9}$ Richard Hillestad et al., Can Electronic Medical Record Systems Transform Health Care? Potential Health Benefits, Savings, and Costs, 24 Health Affairs 1103, 1103 (2005).

${ }^{10}$ Comm. on Quality of Health Care in Am., Inst. of Med., Crossing the Quality Chasm: A New Health SyStem FOR THE 21 st CENTURY (1st ed. 2001).

"Comm. on Quality of Health Care in Am., Inst. of Med., To Err Is Human: Building A Safer Health System (Linda T. Kohn et al. eds., 2000).

${ }_{12}^{12}$ COMm. ON Quality of Heal.th Care, supra note 10 , at 16.

${ }^{13}$ George W. Bush, Addressing Vanderbilt University Medical Center, President Discusses Transforming Health Care for Americans with Health IT (May 27, 2004), available at http://georgewbush-whitehouse. archives.gov/news/releases/2004/05/20040527-5.html.

${ }_{15}^{14}$ See generally Terry, To HIPAA, supra note 3.

${ }^{15}$ Newt Gingrich, Preface to the First Edition, Ctr. for Health Transformation, PAPER KILLS (David Merritt ed., 1st ed. 2007).
} 
Of course, the cost-benefit picture is considerably more muddled. The previously cited RAND study estimate of savings became part of the mythology of EMRs even though the study itself cautioned that a saving of that magnitude was heavily contingent on other major reforms. ${ }^{16}$ Although EMRs have little impact on diagnostic errors, claims that predict EMRs will result in reductions in adverse results and avoidable adverse results, particularly medication errors, are generally viewed as accurate. ${ }^{17}$ Still, further claims of cost savings are made on the basis of better coordination of care, the elimination of duplicate tests, increased patient engagement and all manner of other cost reductions. Looking further into the future, cost savings of a greater order of magnitude are the promised result of analysis of EMR data regarding outcomes and effectiveness. Even greater savings may be forthcoming from data-fueled public health, pharmaceutical and genomic research. Claims in the aggregate aside, it has always been a struggle to establish the positive effect of HIT investment on the bottom line of individual providers. Many apparent benefits are indirect and others depend on providers implementing not only EMRs, but also a broader suite of HIT technologies.

The costs side of the ledger is no less tentative. Some estimates have suggested a total of $\$ 400$ billion for a full national, longitudinal records system. ${ }^{18}$ In 2005 , a study by the Commonwealth Fund estimated a $\$ 44,000$ initial cost per physician in small group or solo practices. ${ }^{19}$ Like the RAND study estimate of benefits, this expenditure number became part of HIT lore and was the figure used to set the maximum MU (Medicare) subsidy. ${ }^{20}$ Estimating the total cost of ownership, such as hardware and software updates, personnel, training, and technical support, has also been difficult (although the Commonwealth Fund report in 2005 estimated $\$ 8,500$ per physician in annual costs for small group or solo practices). ${ }^{21}$ If anything, the negative side of the ledger has more indeterminacies than the benefits side.

\footnotetext{
${ }^{16}$ Hillestad et al., supra note 9, at 1107 ("Achieving savings at the upper end of the range will be limited by the degree of transformation that accompanies HIT").

${ }^{17}$ See, e.g., Jerome Groopman \& Pamela Hartzband, Mindful Medicine: Critical Thinking Leads to Right Diagnosis, ACP INTERNIST (2008), http://www.acpinternist.org/archives/2008/01/groopman.htm. ("While electronic medical records and other computer-based systems are certainly useful, to date, studies have not shown a robust benefit with regard to reducing the rate of misdiagnosis").

${ }^{18}$ Rainu Kaushal et al., The Costs of a National Health Information Network, 143 ANNALS INTERNAL MED. 165,165 (2005).

${ }^{19}$ Robert H. Miller et al., The Value of Electronic Health Records in Solo or Small Group Practices, 24 HEALTH AfFaIRs 1 127, 1130 (2005), http://content.healthaffairs.org/cgi/reprint/24/5/1127.

${ }^{20}$ See Ctrs. For Medicare \& Medicaid Servs., Pub. No. 903695, Medicare Electronic Health Record InCEntive Program for Eligible Professtonals (2010), available at http://www.cms.gov/Outreach-andEducation/Medicare-Learning-Network-MLN/MLNProducts/Downloads/CMS_eHR_Tip_Sheet.pdf. ${ }^{21}$ Id.
} 
Precise financials aside, the imperative of EMR implementation seldom has been challenged. ${ }^{22}$ Yet, progress has been disappointing. In $2010 \mathrm{Dr}$. David Blumenthal, who was President Obama's first head of ONC, decried: "We have years of professional agreement and bipartisan consensus regarding the potential value of EHRs. Yet we have not moved significantly to extend the availability of EHRs from a few large institutions to the smaller clinics and practices where most Americans receive their health care." ${ }^{23}$ This disconnect between aspiration and implementation is a function of cultural barriers and chronic market failures.

Cultural barriers are complex. They can encompass demographic characteristics, such as age or gender, or even preferences among doctors about methods of data entry. ${ }^{24}$ Objections also may reflect technophobia and occasionally are attempts to hide protectionism (such as when technology like telemedicine threatens geographically-based markets). Objectively there are many reasons to support HIT. However, generational and other barriers can get in the way. An Accenture study found that doctors under 50 years old generally believe that HIT has a positive impact on care than their more senior colleagues..$^{25}$ A Deloitte survey found similar differentials based not only on age, but also on size of practice. ${ }^{26}$ Respondents cited cost and operational disruption as the major barriers to HIT adoption. ${ }^{27}$

The Accenture research also found that of the eight developed countries surveyed, the U.S. had significantly lower percentages of doctors who believed HIT improves diagnoses, health outcomes or quality of treatment decisions. ${ }^{28}$ The U.S. health care establishment does appear to be uncomfortable with innovation and views technologically mediated care as related to the industrialization of medicine. Physicians themselves remain antithetical

\footnotetext{
${ }^{22}$ See, e.g., JANet M. Coffman et Al., ON the Road to Meaningful Use of EHRs: A Survey of CaliforNIA PHYSICIANs 6 (2012), available at http:/www.chcf.org/ /media/MEDIA\%20LIBRARY\%20Files/ PDF/R/PDF\%20RoadMeaningfulUseEHRsPhysicians.pdf (noting that "[EHRs] can facilitate improvement in coordination of care, patient safety, quality management, outcomes reporting, and provider efficiency").

${ }^{23}$ David Blumenthal \& Marilyn Tavenner, The "Meaningful Use" Regulation for Electronic Health Records, 363 NEw ENG. J. MED. 501 (2010), available at http://www.nejm.org/doi/full/10.1056/ NEJMp1006114.

${ }^{24}$ See, e.g., Jeffrey A. Linder et al., Method of Electronic Health Record Documentation and Quality of Primary Care, J. Am. MEd. Informatics Ass'N, May 19, 2012, available at doi:10.1136/amiajnl-201 1000788.

${ }^{25}$ Press Release, Accenture, Doctors Agree on Top Healthcare IT Benefits, but Generational Divide Exists, According to Accenture Eight-Country Survey (Jan. 10, 2012), available at http://newsroom. accenture.com/article_display.cfm?article_id $=5370$.

${ }^{26}$ Deloitte Ctr. for Healthcare Solutions, Physician Perspectives About Health Information TechNOLOGY 1, 3 (2012), http://www.deloitte.com/assets/Dcom-UnitedStates/Local\%20Assets/Documents/ Health\%20Reform\%20Issues\%20Briefs/us_chs_PhysicianPerspectivesAboutHIT_021612.pdf.

${ }_{28}^{27}$ Id. at 4.

${ }^{28}$ Accenture, supra note 25.
} 
to performing HIT tasks they have traditionally viewed as staff tasks. Meanwhile, organizations such as the American Medical Association (AMA) are quick to criticize changes that may lead to the commodification of heretofore "professional" skills as industrial models increase pressure to broaden the scope of practice for non- or paraprofessionals. ${ }^{29}$

However, it is market failures (primarily misaligned incentives and associated information asymmetries) that typically are cited as responsible for impeding HIT development. Christensen and Remler identify several failures common to general IT adoption, such as low product differentiation, training costs, switching costs, and the need for interoperability between interlinked or dependent technologies. ${ }^{30}$ However, they argue: "[F]antastic gains of [IT] have outweighed those barriers in most industries and aspects of both public and private life. Why does health care [IT] lag so far behind?"'31 One answer is patient heterogeneity. ${ }^{32}$ Going down that imperfect information road also implicates provider heterogeneity. ${ }^{33}$

Christensen and Remler's primary target is market failure due to misaligned incentives. ${ }^{34}$ Healthcare markets generally are infamous for separating out those who pay (insurers), those who recommend treatment (providers), and those who experience treatment (patients). The EMR problem is a variant on this narrative. Although insurers and patients welcome EMRs, providers are the ones who must pay. If nothing else, this explains why vertically integrated providers (merging as they do the insurance and care functions) appear disproportionately on lists of those who have successfully implemented comprehensive EMRs. ${ }^{35}$

Only a few years into the Bush initiative it became clear that continuing market failure would overwhelm both the Administration's cheerleading

\footnotetext{
${ }^{29}$ Cf. Randall Stross, Advice for the Ill, and Points for the Doctors, N.Y. Times, Feb. 4, 2012, http://www. nytimes.com/2012/02/05/business/on-healthtap-advice-for-you-and-points-for-doctors.html?_r=1\& (AMA president criticizing online physician advice site: "[A] medical history is not taken, a physical exam does not occur and any suggested treatment is not monitored or assessed... Using this information in isolation could pose a threat to patients.").

${ }^{30}$ Michael C. Christensen \& Dahlia Remler, Information and Communications Technology in U.S. Health Care: Why Is Adoption So Slow and Is Slower Better?, 34 J. HeAlTH POLITICS, POL'Y \& L. 1011, 1014-15 (Dec. 2009).

${ }^{31}$ Id. at 1016-17.

${ }^{32}$ Id. at $1017-19$.

${ }^{33}$ Cf. Paul G. Shekelle, Agency for Healthcare Research and Quality, Evidence Report/Technology Assessment: Costs and Benefts of Health InFormation TeChNology 132 (2006), available at http:// www.ahrq.gov/downloads/pub/evidence/pdf/hitsyscosts/hitsys.pdf ("[W]idespread implementation of HIT has been limited by a lack of generalizable knowledge about what types of HIT and implementation methods will improve care and manage costs for specific health organizations").

${ }^{34}$ Christensen \& Remler, supra note 30 , at 1011.

${ }^{35}$ Cf. COFFMAN ET AL., supra note 22, at 14 (reporting that a survey of Californian physicians found that $99 \%$ of Kaiser physicians and $93 \%$ of VA or military physicians had access to an EMR and that those were generally capable of more comprehensive use/tasks).
} 
and important technical standards work. By March 2006, the General Accounting Office was openly critical of ONC's progress. ${ }^{36}$ Two months later, Dr. Brailer resigned to head up an HIT venture capital firm. ${ }^{37}$ In 2007, a disapproving Congress once again slashed the Coordinator's budget and the House Appropriations Committee concluded that ONCHIT had "yet to develop a detailed and integrated implementation plan for achieving the health IT program's strategic goals." ${ }^{38}$ By 2007, the Bush Administration had lost its enthusiasm for the EHR project and pivoted toward Consumer-Driven Health Care (CDHC) and its electronics records analog known as the Personal Health Record (PHR) ${ }^{39}$

Notwithstanding the Bush Administration initiative, by 2009 , only $1.5 \%$ of U.S. hospitals had a comprehensive electronic-records system, while $7.6 \%$ had installed a basic system; computerized provider-order entry for medications was implemented in only $17 \%$ of hospitals. ${ }^{40}$

\section{THE MEANINGFUL USE SUBSIDY PROGRAM}

In the battle against presumed market failure, subsidy was one of the few levers that had not been tried. ${ }^{41}$ Yet subsidy was considered highly unlikely, and even politically impossible. ${ }^{42}$ Then the recession of the late $2000 \mathrm{~s}$ hit hard and ARRA included funding for the Health Information Technology for Economic and Clinical Health Act (HITECH) and that legislation's MU subsidy program. ${ }^{43}$

${ }^{36}$ Health Information Technology: HHS Is Continuing Efforts to Define a National Strategy, Hearing before the Subcomm. on Federal Workforce and Agency Organization of the H. Comm. on Government Reform, 109th Cong. 16 (2006) (Statement of David A. Powner, Dir. Information Tech. Mgmt. Issues), available at http://www.gao.gov/assets/120/113041.pdf.

${ }^{37}$ Joseph Conn, Brailer's Firm to Invest $\$ 700$ Million from CalPERS, Modern HealthCare (June 6, 2007), http://www.modernhealthcare.com/article/20070606/INFO/70606006.

${ }^{38}$ Zach Brennan, Funding Issues Add to Doubts about Future of Health IT Office, IHEalthBeAt (Sept. 20, 2007), http:/www.ihealthbeat.org/Features/2007/Funding-Issues-Add-To-Doubts-About-Futureof-Health-IT-Office.aspx.

${ }^{39}$ See generally Nicolas P. Terry, Personal Health Records: Directing More Costs and Risks to Consumers?, I DreXel L. Rev. 216 (2009).

${ }^{40}$ Ashish K. Jha et al., Use of Electronic Health Records in U.S. Hospitals, 360 New ENG. J. MED. 1628 (2009).

${ }^{41}$ See generally Roger Taylor et al., Promoting Health Information Technology: Is There a Case for More-Aggressive Government Action?, 24 HeALTH AfFAIRS 1234 (2005).

42 J.D. Kleinke, Dot-Gov: Market Failure and the Creation of a National Health Information Technology System, 24 HEALTH AfFalrs 1246, 1257-58 (2005). "The federal government can and should write the huge check and be done with it... [W]riting a check for a quarter of a trillion dollars is pure political fantasy. The very idea of a public works project sounds like an artifact from an era eclipsed by nearly three decades of hostility toward government-based solutions to domestic problems, combined with a seemingly religious belief in marketplace solutions for all of them.' $I d$.

${ }^{43}$ American Recovery and Reinvestment Act of 2009, H.R. 1, 1 lth Cong. $\$ 3005$ (2009), available at http://frwebgate.access.gpo.gov/cgi-bin/getdoc.cgi?dbname=111_cong_bills\&docid=f:hlenr.pdf. 
HITECH provided for a newly energized and powerful ONC along with approximately $\$ 30$ billion in funds for HHS. The majority of those funds were to be dispensed by CMS as staged subsidy payments, ${ }^{44}$ with the remainder available to ONC to provide support, education, and regional grants and loans deigned to promote information exchange. ${ }^{45}$ This section briefly explains the MU program and its escalating "stage" requirements before detailing the Stage 2 process and requirements and the difficulties the latter pose for some providers.

\section{A. Meaningful Use of Certified Records Technology}

As is well known, the core subsidy program, contingent on recipients' satisfaction with MU, provides Medicare incentive payments to non-hospitalbased doctors of up to $\$ 44,000$ over 5 years. Medicaid providers (qualified on the basis of a needy patient floor) qualify for up to $\$ 63,750$ over 6 years. ${ }^{46}$ Approximately 500,000 doctors are eligible. Hospitals will generally qualify for subsidies starting at a $\$ 2$ million baseline with additional sums qualified based on the number of inpatient discharges ${ }^{47}$ It is estimated that a 500-bed hospital would receive $\$ 6.1$ million in incentives. ${ }^{48}$ There are approximately 5000 eligible institutions.

The subsidy process operationalized requires that providers register for the program, ${ }^{49}$ make meaningful use of certified EHR technology, and then attest $t^{50}$ to such qualifying use. Even when all steps are satisfied, the program will not pay the full cost of a provider's EMR program. It is estimated that "US hospitals will need to spend approximately $\$ 120$ billion" while the ARRA

\footnotetext{
${ }^{44}$ Centers for Medicaid and Medicare Services, EHR Incentive Programs (Aug. 27, 2012), https://www. cms.gov/Regulations-and-Guidance/Legislation/EHRIncentivePrograms/index.html?redirect=/EHR IncentivePrograms/.

${ }^{45}$ Office of the Nat'l Coordinator for Health Info. Technology, ONC Initiatives, U.S. Dep't of Health \& Human Servs. (Dec. 7, 2011 ), http://healthit.hhs.gov/portal/server.pt/community/healthit_hhs_gov_ onc.initiatives/1497; see generally David Blumenthal, Launching HITECH, 362 NEw ENG. J. MED. 382 (2010); PwC Health Research Inst., Rock and a Hard Place 2 (Apr. 2009), http://www.pwc.com/us/en/ healthcare/publications/rock-and-a-hard-place.jhtml.

${ }^{46}$ See generally Centers for Medicaid and Medicare Services, Medicare and Medicaid EHR Incentive Programs Basics (Aug. 27, 2012), https://www.cms.gov/Regulations-and-Guidance/Legislation/ EHRIncentivePrograms/Basics.html.

${ }^{47}$ Id.

${ }^{48}$ See generally Rock and a Hard Place, supra note 45, at 3, http://www.pwc.com/us/en/healthcare/ publications/rock-and-a-hard-place.jhtml; Jaime Oh, Lawmakers Introduce Bill That Would Increase Meaningful Use Incentive Payments for Multi-Campus Hospitals, BECKER's Hosp. Rev. (Jul. 14, 2011), http://www.beckershospitalreview.com/healthcare-information-technology/lawmakers-introdu ce-bill-that-would-increase-meaningful-use-incentive-payments-for-multi-campus-hospitals.html.

${ }^{49}$ See generally Centers for Medicaid and Medicare Services, Registration \& Attestation (Aug. 23, 2012), http://www.cms.gov/Regulations-and-Guidance/Legislation/EHRIncentivePrograms/ RegistrationandAttestation.html. ${ }^{50}$ Id.
} 
subsidies will "offset only approximately 15 to 20 percent of total expenditures ... a spending gap of about $\$ 60,000$ to $\$ 80,000$ a bed." $\$ 1$

The subsidy offer has a limited window after which carrots are replaced by sticks. The amount qualified for declines as doctors and institutions hold off on attempting to qualify. Generally, providers needed to register in 2011 or 2012 to claim the maximum subsidy. Thus, 2013 physician latecomers would be eligible for a maximum of $\$ 39,000$ and the class of 2014 for only $\$ 24,000$. $^{52}$ Furthermore, in 2015, Medicare providers who are not meaningful users will be the first to see their government program payments reduced. ${ }^{53}$

An obvious question is why the HHS agencies did not provide all of the subsidy moneys in a single payment. Simply put (and consistent with HITECH's statutory mandate), ONC leadership decided that simple EMR adoption should not be the de facto goal of the project but the means to more ambitious ends. To achieve this, the Administration decided to use an escalation model starting modestly and making staged payments dependent on provider progress. Dr. Blumenthal illustrates this with an escalator metaphor: "We have to get providers on the escalator, get them moving up the escalator, keep them on the escalator toward more and more sophisticated and demanding uses of electronic technologies. ${ }^{.54}$ However, a secondary reason for choosing an escalation model was that the Administration's ambitions for MU went beyond EMR adoption to changing the culture of U.S. healthcare with deep penetration of HIT. As Dr. Blumenthal noted: "[W]e ... don't want the escalator to turn into one of those airport moving walkways where you end up after [a] long trip at precisely the same altitude as where you started." 55

\section{B. A Staged Approach and the MU Matrix}

Once HHS decided to use an escalation model, the MU program was designed around "stages." ${ }^{16}$ Three stages have been announced with a hint of a fourth ${ }^{57}$ Early registrants would face a relatively gentle slope of

\footnotetext{
${ }^{51}$ McKinsey on Business Technology, 20 McKinseY \& Co. 28 (Nov. 20, 2010), http://www.ortechsystems. com/pdfs/MRreformingHospitalsITinvestment.pdf.

${ }^{52}$ Medicare Electronic Health Record Incentive Program for Eligible Professionals (Nov. 2012), https://www.cms.gov/Outreach-and-Education/Medicare-Learning-Network-MLN/MLNProducts/ downloads/CMS_eHR_Tip_Sheet.pdf.

${ }^{53}$ CMS Medicare and Medicaid HER Incentive Programs Milestone Timeline (Aug. 27, 2012), https:/www.cms.gov/Regulations-and-Guidance / Legislation / EHRIncentivePrograms / Downloads / EHRIncentProgtimeline508V1.pdf.

${ }^{54}$ Hannah Fishman, A Discussion with National Health Information Technology Coordinator David Blumenthal, BuRNEsS COMM'N (Apr. 20, 2010), http://www.burnesscommunications.com/burness-effect/ ${ }_{55} 2010$ 2010/4/20/discussion-national-health-information-technology-coordinator-david-blument.

${ }^{56}$ Terry, Certification, supra note 3 , at 50-51.

${ }^{57}$ Id. at 55 .
} 
implementation with subsequent stages increasing in difficulty. ${ }^{58}$ Registrants who later join face initial compliance with the more demanding criteria. ${ }^{59}$

While MU requirements are directed at health care providers, the program's complementary certification standards are aimed at technology vendors ${ }^{60} \mathrm{ONC}$ provides both certification standards and a process whereby vendors can have their products certified. ${ }^{61}$ Not surprisingly, specifications include the ability to record and chart vital signs, the maintenance of active medication and allergy lists, the ability to include laboratory test results, and the capability to generate lists of patients with specific conditions. ${ }^{62}$

The MU criteria (appropriately referred to as the MU matrix, one axis of which is the three-stage implementation timeline) are the outcome goals dictated by the HITECH legislation. ${ }^{63}$ Those goals are: (1) improving the quality, safety, and efficiency of care while reducing disparities; (2) engaging patients and families in their care; (3) promoting public and population health; (4) improving care coordination; and (5) promoting EMR privacy and security. ${ }^{64}$ "Objectives" are a large number of sub-goals derived from those broad HITECH outcome goals. ${ }^{65}$ Examples (in Stage 1) under the quality-safety-efficiency goal included the maintenance of a list of the patient's active medications and recording smoking status. ${ }^{66}$ Under patient engagement, a Stage 1 objective was the provision of clinical summaries for patients after office visits. ${ }^{67}$

"Measures" are the reporting metrics that signify a level of compliance by the provider with the objective. ${ }^{68}$ For instance a Stage 1 measure for the objective of generating prescriptions electronically was that more than $40 \%$ of the provider's prescriptions were transmitted electronically. ${ }^{69}$ Measures are now more routinely normalized around a denominator-numerator-threshold sub-matrix (for example, a denominator might be the EPs total number of

\footnotetext{
${ }^{58} I d$. at 53 .

${ }^{59} \mathrm{Id}$.

${ }^{60} \mathrm{Id}$. at 59.

${ }^{61}$ Id. at 58 .

${ }^{62}$ See Health Information Technology: Initial Set of Standards, Implementation Specifications, and Certification Criteria for Electronic Health Record Technology, 75 Fed. Reg. 44,590, 44,600 (July 28, 2010) (to be codified at 45 C.F.R. pt. 170), available at http://www.gpo.gov/fdsys/pkg/FR-2010-07-28/pdf/ 2010-17210.pdf.

${ }^{63}$ Terry, Certification, supra note 3, at 51 .

${ }^{64}$ See Medicare and Medicaid Programs, Electronic Health Record Incentive Program, Final Rule, 75 Fed. Reg. 44,314, 44,321 (July 28, 2010) (to be codified at 45 C.F.R. pts 412, 413, 422), available at http://www.gpo.gov/fdsys/pkg/FR-2010-07-28/pdf/2010-17207.pdf.

${ }^{65}$ Terry, Certification, supra note 3 , at 51 .

${ }^{66} I d$. at $55-56$.

${ }^{67}$ See Final Rule, supra note 64, at 44,314, 44,370 (Table 2: "Stage 1 Meaningful Use Objectives and Associated Measures Sorted by Core and Menu Set").

${ }^{68}$ See Blumenthal, supra note 45; see also Terry, Certification, supra note 3 , at 51.

${ }^{69}$ Terry, Certification, supra note 3 , at 51.
} 
scans, the numerator the number of such scans accessible from the EHR, and the threshold $40 \%$ ). ${ }^{70}$ To provide flexibility and help keep the escalation slope shallow, providers were given some choices as to where to put their energies. ${ }^{71}$ Thus, Objectives were classified as either "Core" or "Menu."72 While (in Stage 1) providers had to comply with 15 Core requirements, they could choose which of 5 out of 10 Menu Objectives they would comply with. ${ }^{73}$ Providers were also given the approximation of a "get out of jail free card" with "Exclusions," which waived compliance of certain Objectives. ${ }^{74}$

\section{Escalating Requirements in Stages 1 and 2}

Many providers have faced significant barriers in their quest for subsidy payments. ${ }^{75}$ Hospitals have cited "understanding the requirements involved in demonstrating meaningful use" as the greatest barrier followed by "training and change management efforts," "capturing the relevant data electronically as part of clinical workflows," the lack of a dedicated meaningful use team, and "not having the appropriate certified technology."76

Although only a minority of hospitals and health systems were confident that they would meet Stage 1 requirements, ${ }^{77}$ HHS has pushed ahead and published its Meaningful Use Stage 2 rule. ${ }^{78}$ True to the "escalator" model, Stage 2 increases the angle of ascent from Stage 1 while providing softer landings for providers late to the party or facing particular difficulties. Thus, most providers now have two years in each Stage. ${ }^{79}$

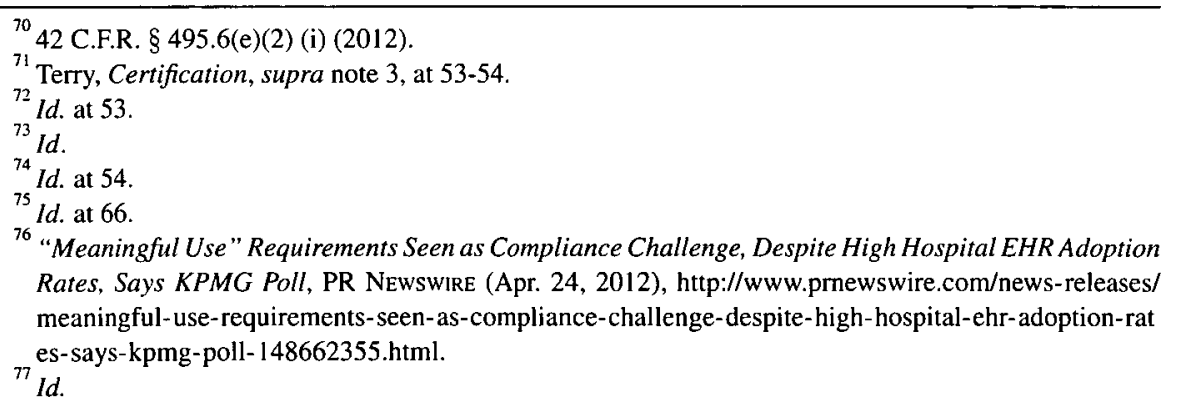

Forty-eight percent of hospital and health system business leaders who participated in a KPMG poll last month said they were confident in their organization's level of readiness to meet Stage 1 meaningful use requirements. Thirty-nine percent said they were somewhat confident, three percent said they were not confident at all, and 10 percent didn't know what their level of readiness was.

${ }_{78} l d$.

${ }^{78}$ Centers for Medicare \& Medicaid Services, Medicare and Medicaid Programs; Electronic Health Record Incentive Program-Stage 2, 77 Fed. Reg. 53,967 (Sept. 4, 2012) (to be codified at 42 C.F.R. parts 412, 413, and 495), available at http://www.gpo.gov/fdsys/pkg/FR-2012-09-04/pdf/2012-21050. pdf.

7977 Fed. Reg. at 53,970 . 
In the Stage 2 rule, CMS retained the basic three-stage model together with the goals-objectives-measures matrix ${ }^{80}$ Stage 2 also kept the core-menu distinction for some objectives. ${ }^{81}$ However, this is tightened up. ${ }^{82}$ Whereas Stage 1 criteria were satisfied by compliance with all 15 core and 5 out of 10 menu objectives, Stage 2 requires EP compliance with 17 core objectives and 3 out of 6 menu objectives.$^{83}$ New menu objectives introduced by Stage 2 include recording family health history and reporting cancer cases to state cancer agencies ${ }^{84}$ Measures are generally increased; for example the $30 \%$ measure for using CPOE to order medications increases to $60 \% .^{85}$

The Stage 2 rule retains most of the Stage 1 objectives and measures. ${ }^{86}$ The major changes are to the "exchange" objective which has been replaced by a new "transitions of care" objective, albeit using a "summary of care" model. ${ }^{87}$ The Stage 1 objective of supplying patients with electronic copies of their health information has been superseded by the online "view and download" objective. ${ }^{88}$ Additionally some Stage 1 objectives have been combined into Stage 2 objectives or otherwise tweaked. ${ }^{89}$ Stage 1's "proof of concept" Public Health Reporting morphs into "successful ongoing submission."

Finally, Stage 2 ramps up the level and sophistication of reporting clinical quality measures, aligning the Physician Quality Reporting Initiative, and reporting associated with Accountable Care Organizations and Patient-Centered Medical Homes. ${ }^{91}$ Overall, Robert Kocher and Bryan Roberts summarized Stage 2 as involving three "transformative" requirements, standardization of data formats for data capture and sharing, patient access and downloading, and quality reporting. ${ }^{22}$

Between the publication of the proposed and final Stage $1 \mathrm{MU}$ rule, HHS gave up considerable ground on the number of mandatory objectives and their measures. ${ }^{93}$ This led Ezekiel Emanuel to comment:

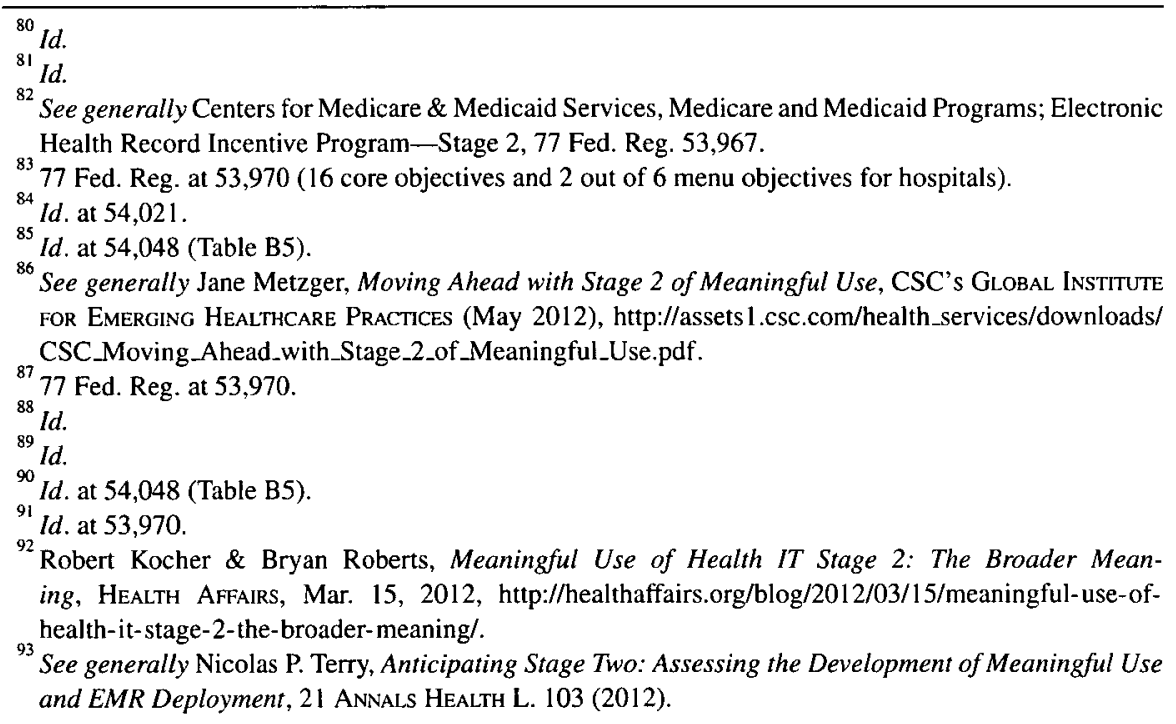


As you might imagine, physicians and hospitals would like to have the incentive payments for meeting minimal requirements. Not surprisingly, when the draft regulations were written, many physicians and hospitals pushed to have them scaled back-and succeeded. The worry is that they will push back again." ${ }^{.4}$

Sure enough, after the publication of the proposed Stage 2 rule, the cycle of protest and negotiation repeated. ${ }^{95}$ HIMSS (the EMR vendors' trade association), the American Hospital Association (AHA), Federation of American Hospitals, the College of Healthcare Information Management, AMA and others reacted to the proposed Stage 2 rule published in March $2012^{96}$ with calls for an extended timeline. AHA said in an April 30 letter to CMS that: "Taken as a whole, the proposed requirements for meeting stage two raise the bar too high and are not feasible for the majority of hospitals to achieve." 97 Similarly, the American College of Cardiology commented: "When the additional workload is coupled with new and constantly changing requirements, it is clear that the burden imposed by CMS through this proposal for Stage 2 goes above and beyond what providers and vendors are capable of addressing before 2014." ${ }^{.98}$

This time, however, HHS did not bend (at least in any major sense) on objectives or measures. ${ }^{99}$ However, the department made another major concession on the timeline. ${ }^{100}$ The final rule delayed the onset of Stage 2 criteria by a year, to 2014 at the earliest. ${ }^{101}$ The reported reason was to give vendors more time to develop the EMR technology to meet the demands of Stage 2. Muted criticism continued, however, with the AMA board chair, noting that "physicians are being held accountable for measures outside their control" and that his organization remained "concerned that physicians have to meet all of the required measures, and failing to meet just one measure

\footnotetext{
${ }^{94} \mathrm{Id}$.

${ }^{95}$ See Medicare and Medicaid Programs, Electronic Health Record Incentive Program-Stage 2, Proposed Rule, 77 Fed. Reg. 13,698 (Mar. 7, 2012) (to be codified at 45 C.F.R. pts 412, 413, 495), available at http://www.gpo.gov/fdsys/pkg/FR-2012-03-07/pdf/2012-4443.pdf.

${ }^{97}$ John Reichard, Washington Health Policy Week in Review: Debate Heating Up over CMS Payments for Health IT, Tне Cомmonwealth Fund (May 2, 2012), http://www.commonwealthfund.org/Newsletters/ Washington - Health - Policy - in - Review/2012/May/May-7-2012/Debate - Heating-Up - Over-CMSPayments-for-Health-IT.aspx.

${ }^{98}$ Jeff Byers, Five Societies Blast CMS with Meaningful Use Opinions, Health Imaging (May 8, 2012), http://www.healthimaging.com/index.php?option=com_articles\&view=article\&id=33934:five-socie ties-blast-cms-with-meaningful-use-opinions.

${ }^{99}$ See generally 77 Fed. Reg. 53,967.

${ }^{100}$ Id. at 53,974 .

${ }^{101}$ Id. at 53,974 (Table 3).
} 
would cause a physician to miss out on incentives and even face financial penalties." 102

\section{III. "MEANINGFUL ADOPTION"}

Optimism (often in the face of provider pushback) has been a hallmark of the EMR initiative. It is not unusual for federal government officials to make optimistic remarks about progress and place an enthusiastic "spin" on any hard numbers. Dr. Blumenthal told us in January 2011 that "[t]he tide is turning" 03 and a 2012 dialog between the present and the first HIT Coordinators (Dr. Farzad Mostashari and Dr. David Brailer) featured non-specific phrases such as "on the march" and "tremendous swelling of interest."104 Also prevalent is "escalator" language. When Stage 2 was announced, Coordinator Mostashari mixed phrases such as "stay the course" with "we can't wait five years to get standards-based exchange." 105 Meanwhile, as MU has been operationalized, federal regulators have access to a growing selection of metrics; "Registered," "Attested," "Received funds," and even the vague "Adopted."

Not surprisingly, studies suggest that physicians in larger practices, or employed by hospitals, are more likely to adopt EMRs. ${ }^{106}$ The correlate also is true; physicians owning their own practices are less likely to use EMRs. ${ }^{107}$ There is greater difficulty in the implementation for smaller practices due to certain "financial, technical, and time barriers"108

According to survey results published by KPMG, $48 \%$ of hospital and health system business leaders were "confident" in their Stage 1 MU readiness, while $39 \%$ were "somewhat confident." ${ }^{109}$ Clearly, pre-MU adopters aside, providers have faced an array of challenges preparing to step on to the MU escalator. The KPMG Poll found the greatest challenges facing hospitals and health systems in meeting Stage $1 \mathrm{MU}$ were comprehending the MU

\footnotetext{
${ }^{102}$ Diana Manos, Negative Reaction to Stage 2: Docs Face Measures "Outside Their Control," HealthCare IT News (Aug. 30, 2012), http://www.healthcareitnews.com/news/negative-reactionmu2-docs-face-measures-outside-their-control.

${ }^{103}$ David Blumenthal, EHR Adoption Set to Soar, The Office of the Nat'l Coordinator Health Info. Tech. (Jan. 13, 2011), http://healthit.hhs.gov/portal/server.pt?open $=512$ \&mode=2\&objID=3357.

${ }^{104}$ David J. Brailer, David Brailer and Farzad Mostashari: Two National Health IT Czars Compare Notes, 31 Health AfFairs 475, 476 (2012).

${ }^{105}$ NPRM for Stage 2 of Meaningful Use Available, Health Data Management (Apr. 11, 2012), http:/l www.healthdatamanagement.com/news/EHR-meaningful-use-Stage-2-details-44055- 1.html.

${ }^{106}$ See, e.g., Catherine M. DesRoches et al., Electronic Health Records in Ambulatory Care-A National Survey of Physicians, 359 NEw ENG. J. MED. 50 (2008).

${ }^{107}$ Albert Boonstra \& Manda Broekhuis, Barriers to the Acceptance of Electronic Medical Records by Physicians from Systematic Review to Taxonomy and Interventions, BMC HEALTH SERv. Res. 12 (2010), http://www.biomedcentral.com/content/pdf/1472-6963-10-231.pdf.

${ }^{108}$ Id. at 14.

109 "Meaningful Use," supra note 76.
} 
requirements $(25 \%)$, "training and change management" $(20 \%)$, data capture $(18 \%)$, staffing $(12 \%)$, and lacking certified technology $(6 \%) .{ }^{110}$

The adoption rates for EMRs under MU raise several sets of questions. First, there are some basically quantitative questions regarding the level of adoption and projections as to future adoption. Second, there are issues about the stragglers and what lies ahead for them. Third, there is a far more difficult question that goes to the qualitative level of adoption-just how many of these freshly minted EMR systems are capable of performing the advanced functions necessary to bring about major quality improvements in the delivery of healthcare?

\section{A. Quantitative Adoption}

Clearly, a significant increase in EMR adoption in U.S. hospitals has occurred over the last few years. The MU program is likely responsible for much of this improvement. A 2012 AthenaHealth survey found that $62 \%$ of physicians are now very familiar with EMRs. ${ }^{11}$ Significant improvement first appeared in California. California is traditionally an early mover in HIT and also is home to the country's largest managed care organization and HITfriendly company, Kaiser Permanente. ${ }^{112}$ According to a California Healthcare Foundation report, physician practices with an EMR in place sharply increased from $3 \%$ in 2005 to $47 \%$ in $2011 .{ }^{113}$ The same report noted gains and improved penetration in larger practices for other types of HIT, such as CPOE, e-prescribing, and decision support. ${ }^{114}$ A 2012 survey using 2011 data from California reported that $71 \%$ of physicians had "some form of EHR at their main practice location." 115 A June 2012 OIG report found that $57 \%$ of physicians participating in Medicare used an EMR in 2011, although only 73\% used certified technology. ${ }^{116}$

Nationally, as shown by the 2012 AHA Annual Survey, the percentage of U.S. hospitals adopting EHRs rose from 16\% to 35\% between 2009 and 2011. ${ }^{117}$ Recent figures for registrations and subsidy payments provided by CMS also tell a positive story. By April 2012, 234,570 EPs (approximately

\footnotetext{
${ }^{110}$ Id

111 AthenaHealth 2012 Physician Sentiment Index, Q6 (June 12, 2012), http://www.athenahealth.com/PSI meaningful-use-incentives.php.

${ }^{112}$ COFFMAN ET AL., supra note 22, at 14 (noting that $99 \%$ of Kaiser physicians had access to an EMR).

${ }^{113}$ The State of Health Information Technology in California, California HealthCaRe Foundation, May 201 1, http://www.chcf.org/publications/201 1/05/health-information-technology-california.

${ }^{114} I d$.

115 Coffman ET AL., supra note 22, at 9.

116 Stuart Wright, Memorandum Report: Use of Electronic Health Record Systems in 2011 among Medicare Physicians Providing Evaluation and Management Services OEI-04-10-00184, at 7, http:// oig.hhs.gov/oei/reports/oei-04-10-00184.pdf.

${ }^{117}$ Dustin Charles et al., The Office of the Nat'l Coordinator for Health Info. Tech., ONC Data Brief (Feb. 2012), http://www.healthit.gov/media/pdf/ONC_Data_Brief_AHA_2011.pdf.
} 
$45 \%$ of the eligible pool of 521,600 and 3,569 out of 5,011 hospitals (approximately $71 \%$ ) had registered for the MU program. ${ }^{118}$ By April 2012, payments totaling $\$ 5$ billion had been paid to approximately 94,000 providers. ${ }^{19}$ These figures show significant increases compared with those of December 2011. ${ }^{120}$ Registration numbers seem generally compatible with earlier estimates from the American Hospital Association that $85 \%$ of hospitals intend by 2015 to take advantage of MU subsidies. ${ }^{121}$ In contrast, the numbers for individual providers are not as positive; the AthenaHealth survey finding that fewer than half of the physicians surveyed in 2012 had attempted to qualify for MU. ${ }^{122}$

While apparently positive (and surpassing HHS's goals ${ }^{123}$ ), these numbers deserve a few caveats. First, it is likely that many of the early disbursements achieved relatively little implementation. This is because prior to $\mathrm{MU}$, many of these early claimants of MU subsidy funds had already installed EMRs. ${ }^{124}$ Second, the rate of registration likely has peaked. For example, the March and April 2012 CMS data show significant declines in new registrations. ${ }^{125}$ Obviously given the escalation model used by ONC, the financial rewards decrease as MU continues. Providers who are late to the MU party will see decreasing financial gains, casting doubts on their commitment to the process (unless, of course, those losses are offset by other benefits derived from the "value of waiting"). ${ }^{126}$

Third, there is reason to believe that the MU actually being achieved by providers is a somewhat watered down version of the already limited Stage 1. A 2012 California HealthCare Foundation survey noted that $71 \%$ of Californian physicians had access to an EMR but found that "only 30[\%] of physicians have EHRs with the functions necessary to achieve all 12 of

\footnotetext{
${ }^{118}$ Ctrs. Medicare \& Medicaid Servs., April 2012 Ehr Incentive Program (Apr. 2012), http://www. cms.gov/Regulations-and-Guidance/Legislation/EHRIncentivePrograms/downloads/Monthly_Paym ent_Registration_Report_Updated.pdf.

${ }^{120}$ Bipartisan Policy Center Task Force on Delivery System Reform and Health IT, Transforming HealthCare: The Role of Health IT. 1, 21 (Jan. 2012), http://bipartisanpolicy.org/sites/default/files/ Transforming\%20Health\%20Care.pdf.

${ }^{121}$ David Charles et al., Electronic Health Record Systems and Intent to Attest to Meaningful Non-Federal Acute Care Hospitals in the United States: 2008-2011, at 2 (Feb. 2012), available at http://www.healthit.gov/media/pdf/ONC_Data_Brief_AHA_2011.pdf.

${ }^{122}$ AthenaHealth, supra note 111, at Q21-22.

${ }^{123}$ U.S. Dep't Health \& Human Servs., News Release, More Than 100,000 Health Care Providers Paid for Using Electronic Health Records (June 19, 2012), available at http:/www.hhs.gov/news/press/ 2012pres/06/20120619a.html.

${ }^{124}$ Josh Israel \& Kimberly Leonard, Health Info. Tech.: Incentives May Not Always Serve Intended Purpose, Center for Public Integrity (Oct. 12, 2011), http://www.iwatchnews.org/201 1/10/12/6934/ health-information-technology-incentives-may-not-always-serve-intended-purpose.

${ }^{125}$ Joseph Conn, EHR Incentive Payments Top $\$ 5$ Billion, Modern HealthCare (June 4, 2012), http:// www.modernhealthcare.com/article/20120604/NEWS/306049987\#ixzz lyGmZNNKi?trk=tynt.

${ }^{126}$ Christensen \& Remler, supra note 30 , at $1022-25$.
} 
the meaningful use objectives measured."'27 A possible implication is that in the state with the highest penetration of HIT, $64 \%$ of physicians either have no EMR or use an EMR that fails to meet Stage $1 \mathrm{MU}$ requirements. A similar disconnect can be found in the IVANS 2012 Provider Survey that found $42 \%$ of providers have implemented EMRs, but that only $37 \%$ have achieved meaningful use of EMR. ${ }^{128}$ Evidence suggests that installed legacy systems and equipment combinations make the higher end MU objectives very difficult to achieve. Such technical deficiencies may also help explain provider difficulties in exchanging information and the increased deferrals or requested exemptions from electronic patient copy at discharge, summary of care at transition, and public health objectives. ${ }^{129}$ As hospitals enter a period of budget tightening, doubts also must arise as to whether they will have funds sufficient to complete some EMR adoptions. ${ }^{130}$

An April 2012 report from the General Accounting Office (GAO) found: "Among participants in the first year of the Medicare EHR program, the majority of providers chose to exempt themselves from reporting on at least one meaningful use measure and many providers reported at least one clinical quality measure based on few-less than seven-patients." 131 Since the GAO also recommended that CMS tighten up its auditing processes, the possibility that there is already a considerable vector between what CMS should be paying for and what providers are actually capable of delivering exists. Put slightly differently, using the words of an insider: "Who would complain that a doctor attested inappropriately? No one, so no one will be audited." 132 Subsequent to the GAO report CMS announced that it would begin audits, though most would only be "desk" audits. ${ }^{133}$

\section{B. The EMR Stragglers}

Based on the numbers so far, a pessimistic scenario would be stabilization of implementation at approximately $50 \%$ of physicians and $75 \%$

\footnotetext{
${ }^{127}$ CoffMAN ET AL., supra note 22 , at 10.

${ }^{128}$ IVANS, 2012 HealthCare Provider Survey 4, 14 (Feb. 2012), available at http://www.ivans.com/ assets/208.pdf.

${ }^{129}$ See Genevieve Douglas, Providers Share Experiences Achieving Meaningful Use, but Challenges Remain, BloOmBerg BNA, Oct. 12, 2011, available at http://www.bna.com/providers-shareexperiences-n12884903856.

${ }^{130}$ See generally David Houle \& Jonathon Fleece, Why One-Third of Hospitals Will Close by 2020, PoLICY (Mar. 14 2012), available at http://www.kevinmd.com/blog/2012/03/onethird-hospitals-close-2020. html.

${ }^{131}$ GAO, First Year of CMS's Incentive Programs Shows Opportunities to Improve Processes to Verify Providers Met Requirements, GAO-12-481, Apr. 30, 2012, http:/gao.gov/assets/600/590538.pdf.

${ }^{132}$ See Ken Terry, AthenaHealth CEO Says Meaningful Use Needs Performance Data, InFormationWeEK (Oct. 10, 2011), http://www.informationweek.com/news/healthcare/policy/231900421 (quoting Jonathan Bush, CEO of AthenaHealth).

${ }^{133}$ Stage 2 Meaningful Use Final Rule Expected by Beginning of September, CMS Official Says, BLoOMBERG BNA, Aug. 15, 2012, http://www.bna.com/stage-meaningful-final-n12884911198/.
} 
of hospitals. However, as later Stages of MU (for example, Stage 2's data exchange requirements) ramp up and assuming that the auditing process is tightened, some of those providers may fall victim to the inadequacies of their chosen EMRs and will be forced off the escalator.

The IVANS 2012 Provider Survey found that $39 \%$ of providers have no plans to implement Stage 1. ${ }^{134}$ At first sight, this seems consistent with the pessimistic scenario outlined. However, the IVANS survey included ineligible MU providers. Critically, many MU orphan hospitals (long-term acute care, rehabilitation, and psychiatric hospitals) are adopting EMRs at a far slower rate (penetration is a lamentable $2-6 \%$ ) than those receiving subsidies. ${ }^{135}$ Nevertheless, this parallel issue should cause concern with regard to quality of care, both within MU providers and those in ineligible environments because of the near impossibility of sharing patient information. ${ }^{136}$

Whether because of ineligibility, failure to register, or fear of potential failure at attestation, it is arguable that a substantial number of providers will continue to lack EMRs. Disproportionately, this will be the case with poorer, rural, or smaller institutions; the very ones that were identified by Dr. Blumenthal as so needing EMRs, those "smaller clinics and practices where most Americans receive their health care." 137 There is a strong connection between high quality hospitals and EMR implementation ${ }^{138}$ and little reason to doubt the negative correlate. Recent evidence suggests the "[w]idening of ... gaps in adoption of EHR systems based on hospital size, teaching status, location, and region of the country" while "[t]he gap based on size, for instance, increased from $15[\%]$ to $22[\%]$, and nonteaching and rural hospitals likewise fell further behind." 139 These impressions have been confirmed by a GAO report noting that of the 2011 hospital recipients of MU funds $67 \%$ were in urban areas and $46 \%$ were very large (top third by number of beds). ${ }^{140}$

The idea that HIT implementation patterns may increase the vector between low and high quality care is further supported by data concerning EMR implementation by physicians. Decker and colleagues comment that

\footnotetext{
${ }^{134}$ IVANS, supra note 128 , at 3 .

${ }^{135}$ See generally Nat'l Council Cmty. Behavioral HealthCare, Hit adoption and Readiness for MeanINGFUL USE IN COMMUNITY BEHAVIORAL HEALTH (June 2012), available at http://www.thenationalcouncil org/galleries/business-practice\%20files/HIT\%20Survey\%20Full\%20 Report.pdf.

${ }^{136}$ Larry Wolf et al., Hospitals Ineligible for Federal Meaningful-Use Incentives Have Dismally Low Rates of Adoption of Electronic Health Records, 31 Health AfFairs 505, 505-13 (2012).

${ }^{137}$ Blumenthal \& Tavenner, supra note 23, at 501.

${ }^{138}$ See, e.g., Elnahal et al., Electronic Health Record Functions Differ Between Best and Worst Hospitals, 17(4) AM. J. Managed CARE 121, 121-47 (2011).

${ }^{139}$ Catherine M. DesRoches et al., Small, Nonteaching, and Rural Hospitals Continue to Be Slow in Adopting Electronic Health Record Systems, 31 Health AfFaIRs 1092, 1097 (2012).

${ }^{140}$ U.S. Gov't Accountability Office, Electronic Health Records: Number and Characteristics of Providers Awarded Medicare Incentive Payments for 2011, GAO-12-778R, at 5 (July 26, 2012), available at http://www.gao.gov/assets/600/593078.pdf.
} 
between 2002 and 2011, "adoption continued to lag for non-primary care specialists, physicians age fifty-five and older, and physicians in small (1-2 providers) and physician-owned practices." than $99[\%]$ of physicians in health maintenance organizations and about 73[\%] of those in academic health centers and other hospitals used an EHR system." 142 The authors conclude that " $t]$ hese patterns continue to show the ability of large practices and those owned by health maintenance organizations and other health care organizations to adopt EHR systems" but that "physicians in these practices make up only a small portion of all practicing office-based physicians."143

\section{Qualitative Adoption}

The possibility that many MU registrants are working with sub-MU technologies is discussed above. This installed base (or some portion of it) may fail properly audited attestation and struggle to comply with future MU stages. ${ }^{144} \mathrm{~A}$ similar question is here posed about the difficulty of those EMRs complying with the data sharing Objectives in the Stage 2 Objectives and questions whether the MU "escalator" will be able to lead providers much further up the slope to sophisticated HIT implementation.

In this article, the term electronic medical record (EMR) has been used almost exclusively, in contrast to electronic health record (EHR). The HITECH definition is neutral, defining an EHR as "an electronic record of health-related information on an individual that is created, gathered, managed, and consulted by authorized health care clinicians and staff." 145 In fact, an EMR is a more limited version of the technology, "a digital version of the paper charts in the clinician's office ... [containing] the medical and treatment history of the patients in one practice." "I46 In contrast, "EHRs are designed to reach out beyond the health organization that originally collects and compiles the information. They are built to share information with other health care providers, such as

\footnotetext{
${ }^{141}$ Sandra L. Decker et al., Physicians in Nonprimary Care and Small Practices and Those Age 55 and Older Lag in Adopting Electronic Health Record Systems, 31 HeALTH AfFairs 1108, 1108 (2012); see COFFMAN ET AL., supra note 22, at 14 (reporting similar findings among California physicians).

${ }^{142}$ Decker et al., supra note 114 , at 1111 .

${ }^{143}$ ld.

${ }^{144}$ David Raths, MU Work Group to Make Initial Stage 3 Recommendations in August, HeALTHCARE INFORMATICS, July 5, 2012, http:/www.healthcare-informatics.com/article/mu-work-groupmake-initial-stage-3-recommendations - august?WA_MAILING LEVEL_CODE $=\&$ spMailingID $=$ 39427252\&spUserID=MzYzODM1ODI2MAS2\&spJobID=149569313\&spReportId=MTQ5NTY5 $\mathrm{MzEzSO}$

${ }^{145}$ Health Information Technology for Economic and Clinical Health Act, 42 U.S.C. § 17921(5) (2006 \& Supp. IV 2010).

${ }^{146}$ Peter Garrett \& Joshua Seidman, EMR vs. EHR-What Is the Difference?, HEalthIT Buzz, Jan. 4, 2011, http://www.healthit.gov/buzz-blog/electronic-health-and-medical-records/emr-vs-ehr-difference/.
} 
laboratories and specialists, so they contain information from all the clinicians involved in the patient's care."147

Such information exchange or sharing is fundamental to MU's stated goals of improving quality, safety, efficiency, patient engagement, promoting public health, and improving care coordination. However, it appears there are far more EMRs than EHRs in use. The delta is currently expressed as the difference between basic (EMRs) and comprehensive (or fully functional) systems (EHRs) ${ }^{148}$ EHRs should be able to exchange information with other EHRs (for example, other providers' systems), share data with patients and external stakeholders such as public health authorities, and share information across an institution's HIT ecosystem (such as with e-prescribing, CPOE, or clinical decision support (CDS) ${ }^{149}$ modules). ${ }^{150}$

The implementation vector between basic and comprehensive systems is not new. ${ }^{151}$ However, it is surprising that the gap remains as high. For example, a recent ONC/AHA survey reported that although almost $35 \%$ of acute care hospitals had adopted EMRs by 2011 , only $8.8 \%$ had comprehensive systems. ${ }^{152}$ Clearly this issue is related to the discussion above; that the low level of technology actually present in the installed bases of EMRs may be hampering compliance with the relatively low threshold of Stage $1 .{ }^{153}$ It also helps explain the strong pushback from providers regarding the data sharing and exchange requirements in the proposed Stage 2 standards. ${ }^{154}$

Although EMRs are a better storage model than paper records, HIT modules in isolation do little improve the safety, quality, or efficiency of healthcare.

\footnotetext{
${ }^{147}$ Id.; see also Dave Garets \& Mike Davis, Electronic Medical Records vs. Electronic Health Records: Yes, There Is a Difference, HIMSS ANALYTICs (2006), http://www.himssanalytics.org/docs/WP_EMR. EHR.pdf (discussing early concepts).

${ }^{148}$ See Prashila Dullabh et al., White Paper: Measurement of the Utilization of an Installed EHR, U.S. Dep't Health \& Human Servs., (2009) (discussing various approaches to assessing the functionality of records technologies), http://aspe.hhs.gov/sp/reports/2009/ehrutil/index.shtml.

${ }^{149}$ What Is Clinical Decision Support?, HIMSS, http://www.himss.org/asp/topics_clinicaldecision.asp ("Clinical Decision Support is a process for enhancing health-related decisions and actions with pertinent, organized clinical knowledge and patient information to improve health and healthcare delivery").

${ }^{150}$ See generally Sharon Silow-Carroll et al., Using Electronic Health Records to Improve Quality and Efficiency: The Experiences of Leading Hospitals, 17 Commonwealth Fund 1 (July 2, 2012), available at http://www.commonwealthfund.org/ /media/Files/Publications/lssue\%20Brief/2012/Jul/ 1608_SilowCarroll_using_EHRs_improve_quality.pdf (detailing comprehensive EMR implementation in nine hospitals).

${ }^{151}$ See Chun-Ju Hsiao et al., Preliminary Estimates of Electronic Medical Record Use by Office-Based Physicians: United States, 2008, National Center for Health STatistics (2008), http://www.cdc.gov/ nchs/data/hestat/physicians08/physicians08.pdf.

${ }_{153}^{152}$ Charles et al., supra note 117.

${ }^{153}$ See supra notes $127-34$ and accompanying text.

${ }^{154}$ See supra notes 86-92 and accompanying text; see also Letter from AMA et al. to Marilyn B. Tavenner (May 7, 2012), available at http://www.ama-assn.org/resources/doc/washington/ehr-stage-2certification-sign-on-letter-07may2012.pdf.
} 
This is also true both for CPOE modules ${ }^{155}$ and e-prescribing systems ${ }^{156}$ when unaccompanied by clinical decision support. The limitations of basic EMRs may also explain recent critical studies of records implementations that have failed to deliver expected increases in care quality. Crosson and colleagues reported a diabetes study showing "that having an EHR as opposed to a paperbased record-keeping system does not guarantee better care and suggest that many practices that have adopted EHRs have not made the necessary changes to both work processes and ways of thinking about care that would lead to improvements in chronic illness management." ${ }^{157}$ More controversially, Romano and colleagues cast serious doubts on the benefits of the new technology by finding: "No association between EHR use and care quality for nineteen indicators and a positive relationship for only one indicator." ${ }^{158}$ The criticism prompted a literature review from ONC staff that suggested a more positive correlation of HIT to improved patient safety. ${ }^{159}$ Many modern studies seem at most ambivalent regarding quality improvements. For example, Appari and colleagues examined process quality among 2011 meaningful use-compliant hospitals. EMR adoption among low-technology hospitals produced a positive quality spike, a very small but measurable improvement in mid-level hospitals, and a significant decline in quality among hospitals seeking to move to post-2011 MU technology levels. ${ }^{160}$

A recent article in Health Affairs opened up a new avenue of EMR criticism. In the article, McCormick argued that HIT-mediated access to prior imaging or blood test results or other physical examinations would increase the ordering of new tests. ${ }^{161}$ The belief brought forward a sharp response from $\mathrm{ONC}$, a defensive re-framing from the Coordinator that " $[\mathrm{t}] \mathrm{he}$ ultimate

\footnotetext{
${ }^{15 s}$ See Karen C. Nanji et al, Errors Associated with Outpatient Computerized Prescribing Systems, $18 \mathrm{~J}$. AM. Med. Informatics Ass'n 767 (2011).

${ }^{156}$ See Johanna I. Westbrook et al., Effects of Two Commercial Electronic Prescribing Systems on Prescribing Error Rates in Hospital In-Patients: A before and after Study, 9 PLoS MEdiciNe 1 (Jan. 31, 2012), available at http://www.plosmedicine.org/article/info\%3Adoi\%2F10.1371\%2Fjournal.pmed. 1001164

${ }^{157}$ See Jesse C. Crosson et al., Typical Electronic Health Record Use in Primary Care Practices and the Quality of Diabetes Care, 10 AnNals FAM. MED. 221 (May/June 2012); Daria O'Reilly et al., CostEffectiveness of a Shared Computerized Decision Support System for Diabetes Linked to Electronic Medical Records, 19 J. AM. MED. InFormatics Ass'N 341 (2012) (showing only marginal improvement in trial involving treatment of diabetes type 2).

${ }^{158}$ Max J. Romano \& Randall S. Stafford, Electronic Health Records and Clinical Decision Support Systems: Impact on National Ambulatory Care Quality, 171 ARCHIVES INT. Med. 897, 901 (2011).

159 Melinda Beeuwkes Buntin et al., The Benefits of Health Information Technology: A Review of the Recent Literature Shows Predominantly Positive Results, 30 Health AfFairs 464, 464 (2011).

${ }^{160}$ Ajit Appari et al., Meaningful Use of Electronic Health Record Systems and Process Quality of Care: Evidence from a Panel Data Analysis of U.S. Acute-Care Hospitals, HeAlTH SERvices ResEarCh, July 20, 2012, http://onlinelibrary.wiley.com.proxy.lib.siu.edu/doi/10.1111/j.1475-6773.2012.01448.x/pdf.

${ }^{162}$ Danny McCormick, Giving Office-Based Physicians Electronic Access to Patients' Prior Imaging and Lab Results Did Not Deter Ordering of Tests, 31 Health AfFairs 488, 493 (2012).
} 
impact of EHRs on reducing cost will be through improvements in the coordination and quality of care, and the prevention of unnecessary and costly complications and hospitalizations."162

Possibly because of Dr. Brailer's background in information exchanges, the Bush Administration made a priority of promoting of interoperability between records systems. ${ }^{163}$ The MU project, particularly Stage 1, has focused more on clinical applications such as robust recording of health information. ONC has relied on its other, more modest funding mechanisms to encourage health information exchange. ${ }^{164}$ Not surprisingly, evaluations of data exchange have showed only limited progress. ${ }^{165}$ In 2010 , MU's approach to data exchange was strongly criticized by the President's Council of Advisors on Science and Technology (PCAST) ${ }^{166}$ PCAST characterized ONC's data sharing plans as "very modest" and instead urged a "simultaneous focus on the capability for universal data exchange, able to unleash the power of the competitive market, to produce increasingly better and less expensive systems, and to create the 'network effect' that spurs further adoption." 167 PCAST insisted the use of a "'universal exchange language' that enables health IT data to be shared across institutions; and also to create the infrastructure that allows physicians and patients to assemble a patient's data across institutional boundaries. ..."168

In 2011, ONC responded with a moderate proposal for metadata standards that could facilitate the exchange of summary patient records. ${ }^{169}$ The more recent Bipartisan Policy Center (BPC) report, Transforming Health Care: The Role of Health IT, listed the "Lack of Health Information Exchange" as one of the primary barriers to high performance healthcare. Specifically, BPC identified limited Stage 1 MU requirements, lack of a robust

${ }^{162}$ Dr. Farzad Mostashari, Recent Study: Get the Facts, HealthITBuzz (Mar. 6, 2012), http://www.healthit. gov/buzz-blog/meaningful-use/study-facts/; see also Janet Marchibroda, Does Health IT Reduce Costs or Not?, BIPARTISAN POLICY CTR. Blog (Mar. 14, 2012), http://www.bipartisanpolicy.org/blog/2012/03/ does-health-it-reduce-costs-or-not.

${ }^{163}$ See generally Timothy Mullaney, This Man Wants to Heal Healthcare, BloOMBerg Businessweek, Oct. 30, 2005, http://www.businessweek.com/magazine/content/05_44/b3957113.htm.

${ }^{164}$ See, e.g., Nationwide Health Information Network, HEALTH IT, http://healthit.hhs.gov/portal/server.pt/ community/healthit_hhs_gov_nhin_exchange/1407.

${ }^{165}$ Robert H. Miller, Satisfying Patient-Consumer Principles for Health Information Exchange: Evidence from California Case Studies, 31 Health AfFaIRs 537 (2012).

${ }^{166}$ See President's Counsel Advisors Sci. \& TeCh., Report to the President Realizing the Full Potential. of Health Information Technology to Improve HealthCare for Americans: The Path Forward (2010).

${ }^{167} I d$. at 3.

${ }^{168} I d$. at 4.

${ }^{169}$ Metadata Standards to Support Nationwide Electronic Health Information Exchange, 76 Fed. Reg. $48,769,48,776$ (Aug. 9, 2011). 
infrastructure to support exchange (with little enthusiasm for ONC's " $\mathrm{Di}$ rect Project" model ${ }^{170}$ notwithstanding its recent growth in adoption ${ }^{171}$ ), and, echoing PCAST, a lack of sufficiently sophisticated data standards. ${ }^{172}$

\section{QUALITY, SATISFACTION, AND SAFETY}

As with many products and services (particularly complex ones), HIT products will exhibit negative externalities. In the case of EMRs, most attention has been directed at their privacy and security risks. ${ }^{173}$ In contrast, one of the themes explored herein has been that the installed base of EMRs is underperforming. Either EMRs are not being used to their fullest extent to perform MU tasks or the systems deployed are quite limited in their capabilities. Either way, there is suspicion that EMR flaws are responsible for failure to meet current MU stages and are unlikely to be capable of the comprehensive or interoperable levels of use expected in the future by the MU architects. Lack of specifications and poor usability illustrate only part of the underperformance narrative. Poor design or manufacture also brings into play safety regimes such as FDA device regulation, product liability, and medical malpractice.

\section{A. Quality and Satisfaction}

A 2011 survey of Californian physicians suggested that physicians are less than satisfied with their EMR experiences. ${ }^{174}$ Although the 2012 AthenaHealth survey found that $71 \%$ of physicians were generally positive about EMRs, it reported that a large percentage of physicians considered the technology expensive to purchase, install and maintain. ${ }^{175}$

Historically, EMRs have been designed to answer the needs of hospitals (of which pre-MU was the only sizeable market) and are less sensitive to patient and provider heterogeneity. ${ }^{176}$ Today, a declining number of physicians

\footnotetext{
${ }^{170}$ See generally Direct Project, Office of the National Coordinator for Health Information TechNOLOGY (Aug. 2, 2012), http://healthit.hhs.gov/portal/server.pt/community/healthit_hbs_gov_direct_ project/3338.

${ }^{171}$ Brett Andriesen, Bright Spots of the Direct Project Adoption, HealthITBuzz (June 18, 2012), http:// www.healthit.gov/buzz-blog/state-hie/the-direct-project-adoption/.

${ }^{172}$ See generally Transforming Health Care: The Role of IT, BIPARTISIAN POLICY CENTER, Jan. 27, 2012, http://www.bipartisanpolicy.org/news/multimedia/2012/02/transforming-health-care-role-health-it.

${ }^{173}$ Nicolas P. Terry \& Leslie P. Francis, Ensuring the Privacy and Confidentiality of Electronic Health Records, 2007 U. Ill. L. Rev. 681, 683.

${ }^{174}$ Coffman ET Al., supra note 22 , at 13 (reporting that a survey of California physicians found only $35 \%$ "very satisfied" with their EMRs and $38 \%$ "somewhat satisfied").

${ }^{175}$ AthenaHealth, supra note 111, at Q11, Q17.

${ }^{176}$ See, e.g., Katherine Rourke, Why Hospitals Can't Talk EMRs with Doctors, HosPrTAL EMR \& EHR, Sept. 1, 2011, http://www.hospitalemrandehr.com/2011/09/01/why-hospitals-cant-talk-emrs-with-doctors/.
} 
believe that EMRs were designed with them in mind. ${ }^{177}$ Generally, physicians are now taking less of an active role in purchasing EMRs for their practices. ${ }^{178}$

ONC is attempting to increase market transparency through improved versions of its online Certified Health IT Product List (CHPL). ${ }^{179}$ There are large numbers of EMR vendors, with over 200 listed as having supplied a product that was meaningfully used. ${ }^{180} \mathrm{~A}$ recent $\mathrm{OIG}$ report noted that just nine vendors supplied $60 \%$ of Medicare physicians. ${ }^{181}$ Overall, the EMR market does not seem to work very well. This is in part because the various EMR products are proprietary. Vendors, therefore, are able to practice technological "lock-in," relying on the proprietary nature of EMRs and the data formats they use to make it very difficult for providers to move to other products, ${ }^{182}$ even when a superior competing product emerges. Moving between products during meaningful use is particularly difficult. ${ }^{183}$ The proprietary nature of EMRs has other implications. This is a time of considerable merger activity among health care providers. Yet combining incompatible HIT systems during MU is a considerable challenge. ${ }^{184}$ Consolidation of HIT vendors can also cause problems. This was illustrated by the testimony of a dermatologist before a House panel; she reported a difficult transition to an EMR causing sharp decline in patient volume, only to be followed by the acquisition of her EMR vendor by a company that did not support her network. ${ }^{185}$

Consistent with one of the narrative themes of this article-that EMRs and related HIT modules are not very good and may be impeding MU-are recent criticisms of EMR usability. According to the AMA, "[t]here is a direct correlation between EHR adoption and the usability of an EHR."186 A

\footnotetext{
${ }^{177}$ AthenaHealth, supra note 111 , at Q15.

${ }^{178}$ Id. at Q9.

${ }^{179}$ Mary Mosquera, ONC Improves Usability of Online Certified EHRs List, GovernmEnt HealthIT (June 25,2012 ), http:/www.govhealthit.com/news/onc-improves-usability-online-certified-ehrs-list?topic= 08 .

${ }^{180}$ Joseph Conn, Few EHR Vendors Dominate Payments, Modern HealthCare.com (Jan. 13, 2012), http:// www.modernhealthcare.com/article/20120113/NEWS/301139989.

${ }^{181}$ WRIGHT, supra note 116 , at 8.

${ }^{182}$ Sarita Harbour, What Is a Vendor Lock-In?, Houston CHroN., http://smallbusiness.chron.com/vendorlockin-33663.html.

${ }^{183}$ See, e.g., John Lynn, Meaningful Use Provides Hospital EHR Vendor Lock In, HoSPITAL EMR \& EHR (Apr. 10, 2012), http://www.hospitalemrandehr.com/2012/04/10/meaningful-use-provideshospital-ehr-vendor-lock-in/.

${ }^{184}$ Joel Schectman, For Hospital CIOs, Mergers Complicate Move to Electronic Records, CIO J., June 13, 2012, http://blogs.wsj.com/cio/2012/06/13/for-hospital-cios-mergers-complicate-moveto-electronic-records/.

${ }^{185}$ Not What the Doctor Ordered: Barriers to Health IT for Small Medical Practices: Hearing before the H. Subcomm. on Health Care and Technology, 112th Cong. 18-20 (2011) (statement of Sasha Kramer, M.D.), http://www.gpo.gov/fdsys/pkg/CHRG1 12hhrg68062/html/CHRG1 12hhrg68062.htm.

${ }^{186}$ Statement by the American Medical Association, Health IT Policy Committee Certification/Adoption Workgroup 1 (Apr. 21, 2011), http://healthit.hhs.gov/portal/server.pt/directory/april_21\%2C_2011. cawg/18327?DirMode $=1$.
} 
large number of usability issues seem associated with interface design and usability, including data sorting costs. In 2011, during testimony before the ONC Certification/Adoption Workgroup, an Iowa internist detailed some of the current frustrations with EMR interfaces: "Improvements in usability are urgently needed to address [a] widespread experience of overwhelm" and noted the cognitive workload for physicians trying to mentally reorganize data that is poorly organized in EMRs.

It cannot be assumed that simply because a piece of information is somewhere within the EHR that it will be easily available to the clinicians caring for the patient. It may be buried in an inaccessible location or overlooked because of poor information display. ${ }^{187}$

By way of illustration, Gawande has related how his EMR software did not include (some admittedly rare) diseases forcing him to use "other" on the pull-down menu. ${ }^{188}$

It is likely that some usability problems are functions of transitioning staff from paper to electronic systems and will improve or disappear over time ${ }^{189}$ However, empirical studies increasingly support the position that there are persistent usability issues in the current generation of HIT. In a RAND study, Ridgely and Greenberg critically examine Drug-Drug Interaction (DDI) alerts initiated by CDS systems. Specifically, they explore two related phenomena; the first being the tendency of CDS to generate a very large number of DDI alerts that leads to "alert fatigue" suffered by physicians. ${ }^{190}$ Russ and colleagues have found similar dysfunction relating to "inadequate alert interface design" in CPOEs. ${ }^{191}$

The confrontation of usability issues is still quite immature and a major challenge. One National Institute of Standards and Technology (NIST) scientist described usability as "often ... an afterthought in the

\footnotetext{
${ }^{187}$ Written testimony of Christine A. Sinsky before Certification/Adoption Workgroup Usability Panel 2 (Apr. 21, 2011), http://healthit.hhs.gov/portal/server.pt?open=space\&name=Dir\&id=cached\& psname $=$ Dir \&psid $=1 \&$ in _hi $\_$userid $=10741 \&$ cached $=$ true $\&$ control $=$ DirRepost $\&$ rangeFrom $=21 \&$ range $\mathrm{To}=25 \&$ subfolderID $=18327 \&$ DirMode $=1$.

188 Atul Gawande, The Checklist Manifesto: How to Get Things Right 22 (2009).

${ }^{189}$ See, e.g., Kirk Johannesen, Columbus Hospital Blames Electronic Records for Rising ER Waits, INDIANAPOLIS STAR, Aug. 8, 2012, http://www.indystar.com/article/20120808/NEWS/120808018/ Columbus-hospital-blames-electronic-records-rising-ER-waits (reporting doubling of patients' lengths of stay in a hospital emergency department during transition to EMR).

${ }^{190}$ M. Susan Ridgely \& Michael D. Greenberg, Too Many Alerts, Too Much Liability: Sorting through the Malpractice Implications of Drug-Drug Interaction Clinical Decision Support, 5 ST. Lous U. J. Health L. \& Pol'y 257, 259 (2011-2012).

191 Alissa L. Russ et al., Prescribers' Interactions with Medication Alerts at the Point of Prescribing: A Multi-Method, in Situ Investigation of the Human-Computer Interaction, 81 INT'L J. MED. INFORMATICS 232, 240 (2012)
} 
industry." 192 In 2012, NIST requested EMRs from vendors to begin a yearlong study on usability to "(1) Develop a set of guidelines/standards for the usability of HIT/EHRs, and (2) develop a framework for assessing EHR usability."193 Improving how physicians interact with HIT and integrate technology into their workflows will be fundamental to the success of programs like MU. Eric Topol has described the use of an EMR during a patient encounter as follows: "Rather than looking the patient in the eye, the physician is looking at a screen and typing in the data. Most doctors are uncomfortable typing and are slow and prone to making errors." 194 The implications may be profound for the physician-patient relationship. As Topol further opines:

So in the mind of the physician, a lot of insight is missing as result of less direct communication with patient and less ability to freely express one's thoughts. Symmetrically, the patient feels less direct contact and is often disturbed by the doctor's pecking on the keyboard and looking at the screen. The sense of not being heard or understood is often prompted by this distracted, electronically fettered encounter. ${ }^{195}$

The large number of providers that now employ medical scribes to record the medical encounter in the EMR provides strong evidence of the seriousness of this issue. ${ }^{196}$ As described by one medical administrator: "The solution was to take the doctors off the computer, put them at the bedside, and let the scribe do the transcription. It's been a huge success. The physicians love it."197 The practice is becoming widespread enough that the Joint Commission has issued guidelines as to the use of scribes. ${ }^{198}$ In itself, however, this practice provides a metaphor for the failings of the current generation of EMRs (at least in their user interface) and casts doubt on some of the claims made for the cost-savings they bring.

\footnotetext{
${ }^{192}$ Kenny Goldberg, iHealthBeat Special Report: Health Care Industry Struggle with Usability of Electronic Health Record Systems, IHEalthBeat, June 13, 2012, http://origin.eastbaymedia.com/ advisoryboard/podcast_media/iHBSpecialReportTranscript061312.pdf.

${ }^{193}$ Evaluating the Usability of Electronic Health Record (EHR) Systems, 77 Fed. Reg. 8,217 (Feb. 14, 2012), http://www.gpo.gov/fdsys/pkg/FR-2012-02-14/html/2012-3415.htm; see also Lowry et al., Technical Evaluation, Testing and Validation of the Usability of Electronic Health Records, NAT'L INST. OF SCI. AND TECH. INTERAGENCY REP. 7804 (Feb. 21, 2012), http://www.nist.gov/customcf/get_pdf.cfm? pub_id $=909701$.

194 Eric Topol, The Creative Destruction of Medicine: How the Digital Revolution Will Create Better Health Care 150 (2012).

${ }^{195}$ Id.

${ }^{196}$ Harris Meyer, Scribes Are Doctors' Tech Support, L.A. TimEs, Sept. 6, 2010, http://articles.latimes. com/2010/sep/06/health/la-he-medical-scribes-20100906.

${ }_{197}^{19}$ Id. (quoting Dr. Robert Steele, Loma Linda University Medical Center).

${ }^{198}$ Human Resources (CAMCAH/Critical Access Hospitals): Use of Unlicensed Persons Acting as Scribes, ThE JOINT COMmISsion (July 12, 2012), http:/www.jointcommission.org/standards_information/ jcfaqdetails.aspx?StandardsFAQChapterld=19\&StandardsFAQId=426.
} 


\section{B. Technological Iatrogenesis}

There is cogent evidence that increased EMR use will reduce provider errors and decrease malpractice claims. ${ }^{199}$ However, and not without irony, "[w]hile hospital electronic medical records (EMR) are intended to reduce medical errors, several aspects of the EMR may actually increase the incidence of certain types of errors or produce new safety risks that result in harm."200 Medical errors caused by the increased use of technological innovations are an issue of growing importance. ${ }^{201}$

In 2010, the Food and Drug Administration (FDA) disclosed that even without any formal reporting system, it had recorded 260 "HIT-related malfunctions" in the preceding two years. ${ }^{202}$ The IoM broadly agrees, stating in its November 2011 report, Health IT and Patient Safety: Building Safer Systems for Better Care, that "[d]esigned and applied inappropriately, health IT can add an additional layer of complexity to the already complex delivery of health care, which can lead to unintended adverse consequences, for example dosing errors, failure to detect fatal illnesses, and delayed treatment due to poor human-computer interactions or loss of data." ${ }^{203}$ Certainly a significant number of physicians perceive an increase in errors associated with EMR adoption. ${ }^{204}$

Although understanding the error profiles of EMRs is immature, the FDA already has created a four-part taxonomy: errors of commission, errors of omission or transmission, errors in data analysis, and technological incompatibility between multi-vendor applications and systems. ${ }^{205}$ The origins of these errors may also be subjected to broad classification. According to Harrington and colleagues: "Threats to patient safety can be introduced during any phase of the EMR lifecycle, such as planning, design, development, testing, implementation, operations, and maintenance. Within each of these processes, technology, people, and the work environment can individually or collectively generate errors." 206

\footnotetext{
${ }^{199}$ Mariah A. Quinn et al., The Relationship between Electronic Health Records and Malpractice Claims, 172 ARCHIVEs INT. MED. 1187, 1188 (2012).

${ }^{200}$ Harrington et al., Safety Issues Related to the Electronic Medical Record (EMR): Synthesis of the Literature from the Last Decade, 2000-2009, 56 J. HealthCare Mgmt. 31, 32 (2011).

${ }^{201}$ See, e.g., Joel Schectman, Philips Recalls Flawed Patient Data System, Wall St. J., July 20, 2012, http://blogs.wsj.com/cio/2012/07/20/philips-recalls-flawed-patient-data-system/.

${ }^{202}$ Hit Pol'y Comm. Adoption/Certification Workgroup, Testimony of Dr. Jefreey Shuren, Director OF FDA's Center for Devices and Radiological Health 2 (Feb. 25, 2010), available at http://healthit. hhs.gov/portal/server.pt/gateway/PTARGS_0_11673_910717_0_0_18/3Shuren_Testimony022510.pdf.

${ }^{203}$ Inst. Med., Health IT and Patient Safety: Building Safer Systems for Better Care 2 (2012), available at http://iom.edu/Reports/2011/Health-IT-and-Patient-Safety-Building-SaferSystems-for-Better-Care.aspx.

${ }^{204}$ DesRoches et al., supra note 106, at 57.

${ }^{205}$ HIT POL'y COMM., supra note 202, at 2.

${ }^{206}$ Harrington et al., supra note 200, at 31-43.
} 


\section{Device Regulation}

As the profile of safety issues involving EMRs and related HIT technologies has increased, so has the likelihood of federal safety regulation. ${ }^{207}$ Technically, EMRs should be able to perform their own post-marketing surveillance and that of connected HIT devices. However, as currently regulated, the Certification standard does not address the issue of EMR errors and their potential adverse effect on patient safety. In 2008, Hoffman and Podgurski canvassed the options for EMR regulation, ${ }^{208}$ concluding that a new agency would be preferable to the FDA and that "an adequately funded agency focused exclusively on HIT, with a concentration of technical talent and expertise, could be an effective vehicle for regulating EHR systems."209 As MU came online, the issue of appropriate regulation became politically charged. The FDA characterized its regulatory inaction as an exercise of discretion as it evaluates the field. ${ }^{210}$ However, the HIT industry and ONC took the position that safety regulation would slow down innovation and implementation by inhibiting innovation and increasing costs. ${ }^{211}$

In 2010 , the IoM was asked to recommend a resolution of the issue. In a November 2011 report in Health IT and Patient Safety: Building Safer Systems for Better Care, the IoM apparently sided with ONC. It recommended that a new entity, the Health IT Safety Council, should be established within HHS to collect and provide information and set safety standards. ${ }^{212}$ Reacting to the report, ONC Coordinator Mostashari commented: "HHS agrees with IOM that more can and should be done to capture safety issues unique to EHRs when and if they arise. ONC will lead an HHS planning initiative to develop a comprehensive EHR safety action and surveillance plan well within the 12-month period recommended by IOM." 213 That timeline may be coming under critical scrutiny. In June 2012, Congresswoman Ellmers, the chair of the

\footnotetext{
${ }^{207}$ See generally Fred Schulte \& Emma Schwartz, Electronic Medical Record Shift: Signs of Harm Emerge as Doctors Move from Paper, Huffington Post, May 25, 2011, http:// www.huffingtonpost.com/2010/04/20/electronic-medical-record_n_545441.html.

${ }^{208}$ Sharona Hoffman \& Andy Podgurski, Finding a Cure: The Case for Regulation and Oversight of Electronic Health Record Systems, 22 HARV. J.L. \& TECH. 103, 126-40 (2008).

${ }^{209}$ Id. at 140 .

${ }^{210}$ HIT POL'Y CoMm., supra note 202, at 3.

${ }^{211}$ Fred Schulte \& Emma Schwartz, FDA Considers Regulating Safety of Electronic Health Systems, HuFFINGTON Post, May 25, 2011, http://www.huffingtonpost.com/2010/02/23/fda-considers-regulating_n_ 474137.html; Neil Versel, FDA, ONC Clash over EMR Safety Issues, Fierce EMR (Aug. 5, 2010), http://www.fierceemr.com/story/fda-onc-clash-over-emr-safety-issues/2010-08-05; Milt Freudenheim, Panel Set to Study Safety of Electronic Patient Data, N.Y. Times, Dec. 13, 2010, http://www. nytimes.com/2010/12/14/business/14records.html?_r=0; Mary Mosquera, HHS Panel Endorses Patient Safety Database, Government HealthIT (Apr. 22, 2010), http://www.govhealthit.com/news/ hhs-panel-endorses-patient-safety-database.

${ }^{212}$ INST. MED., supra note 203, at 3.

${ }^{213}$ Farzad Mostashari, Improving Patient Safety through Health IT, Health IT BUZz, Nov. 8, 2011 , http: //www.healthit.gov/buzz-blog/electronic-health-and-medical-records/patient-safety-healthit/
} 
House Small Business Subcommittee on Healthcare and Technology, wrote to Secretary Sibelius requesting, inter alia, all available data on HIT-related risks adverse results and the specifics of HHS's plan to minimize safety risks. ${ }^{214}$

Overall it is difficult to see FDA withdrawing completely from the field. Dissenting from the IoM HIT safety report, Dr. Richard Cook argued that leaving "quality, accuracy, precision, reliability, and safety" in the hands of the vendors "is unacceptable for health IT that must provide high-level performance in a hazardous environment." Dr. Cook concluded that "health IT is a medical device. ... It should be regulated as a medical device now and should have been regulated as a medical device in the past."215

The regulatory agency's responses to calls for action have been restrained. In 2010, Dr. Jeffrey Shuren, director of the FDA's Center for Devices and Radiological Health, testified that "FDA has largely refrained from enforcing our regulatory requirements with respect to HIT devices." ${ }^{.16} \mathrm{~A}$ few months later, Dr. Shuren admitted that "[a]s of right now we're not regulating EHRs, and it may turn out that we won't," while acknowledging that "EHRs touch all kinds of medical devices that we have been regulating for a long time, and they impact the functioning of those technologies."217

There are several regulatory models that the FDA could follow. EMRs could be subject to premarket regulation, such as Premarket Notification (Class 1 or 2 devices) ${ }^{218}$ or Premarket Approval (Class 3 devices), or less taxing postmarket controls, such as voluntary or mandatory surveillance. ${ }^{219}$ However, it is important to remember the IoM's conclusion that while "Instances of health IT-associated harm have been reported," "little published evidence could be found quantifying the magnitude of the risk." 220 It is at least likely that FDA is biding its time, documenting more adverse results, while building a strategy for regulating both existing devices and future challenging technologies, such as mobile medical applications that run on smartphones. The agency's 2011 Draft Guidance on Mobile Medical Applications committed to the regulation of medical mobile applications "used as an accessory to a regulated medical

${ }^{214}$ Letter from Renee L. Ellmers, Chairwoman, U.S. H.R. Comm. Small Bus., to Kathleen Sebelius, Sec'y, U.S. Dep't Health \& Human Servs. (June 2, 2012), available at http://smbiz.house.gov/UploadedFiles/ Sebelius_Health_IT_IOM_report_followup_6_12_12.pdf.

${ }^{215}$ INST. MED., supra note 203, at 197.

${ }^{216}$ HIT PoL'y Coмm., supra 202, at 2.

${ }^{217}$ David Raths, Report from PharmEHR Summit: Will FDA Regulate EHRs?, HEALTHCARE INFORMATTCS, Apr. 8, 2011, available at http://www.healthcare-informatics.com/article/ report-pharmehr-summit-will-fda-regulate-ehrs (quoting Dr. Shuren).

${ }^{218}$ Note that the agency recently reclassified so-called Medical Device Data Systems (basically conduit, storage, or display components) to Class 1. Medical Devices, Medical Device Data Systems, 76 Fed. Reg. 8,637, 8638 (Feb. 15, 2011).

${ }^{219} 21$ U.S.C. § 360c (2012); see generally U.S. Food and Drug Admin., Overview of Device Regulation (Aug. 31, 2009), available at http://www.fda.gov/MedicalDevices/DeviceRegulationandGuidance/ Overview/default.htm.

${ }^{220}$ INST. MED, supra note 203, at 3 (emphasis in original). 
device" or one that "transforms a mobile platform into a regulated medical device."221 The same guidance specifically excluded "Mobile apps that perform the functionality of an electronic health record system or personal health record system,",222 suggesting the agency will apply a different regulatory model to EMRs.

The FDA knows that EMR safety regulation is both technically difficult and a "political hot potato." ${ }^{.23}$ It is also inevitable. As a result, it is probable that the agency will allow the MU program to progress further along (or even to the end of) its timeline without regulatory intervention lest it be accused of hindering implementation.

\section{Liability Models}

With safety regulation politicized, it may be that the first formal scrutiny of the safety of EMRs, and their appropriate use, will take place in the courts. I first raised these issues a decade ago, arguing that "likely adverse event scenarios that will result from technologically-mediated diagnosis, treatment and care will severely test our current torts operational rules, particularly those that lie at the intersection of malpractice and products liability."224 Hoffman and Podgurski have clearly detailed the types of allegations and causes of action that likely will play out. ${ }^{225}$

A recent case commentary posted on AHRQ's Morbidity and Mortality Rounds is illustrative of the complex issues. A nursing home resident suffering from dementia was admitted to a hospital. As a prelude to removing his feeding tube, the care team increased his dose of anticoagulant. Subsequently, the team decided to schedule an echocardiogram to determine whether to continue with the anticoagulant. The attending physician instructed a resident to temporarily stop the anticoagulant. The latter initiated the order on the CPOE application on her smartphone but was interrupted by a personal text message. The patient

${ }^{221}$ U.S. Food and Drug Admin., Draft Guidance for Industry and Food and Drug Administration StafF-Mobile Medical Applications 7 (July 21, 2011), available at http://www.fda.gov/ medicaldevices/deviceregulationandguidance/guidancedocuments/ucm $263280 . \mathrm{htm}$.

${ }^{222}$ Id. at 10 .

${ }^{223}$ Raths, supra note 217 (quoting Dr. Shuren).

${ }^{224}$ See generally Nicolas P. Terry, When the Machine That Goes "Ping" Causes Harm: Default Torts Rules and Technologically-Mediated Health Care Injuries, 46 ST. Lous U.L.J. 37 (2002); see also Thomas v. United States, 660 F. Supp. 216, 218 (D.D.C. 1987).

The records were summary in nature and did not document plaintiff's condition to the degree necessary for the proper monitoring of his condition. For instance, the records did not adequately describe the location or the relative progression of the swelling, nor provide details of any medical examinations performed. Thus the records did not provide the next attending physician with adequate information for him to perform his duties.

${ }_{225}$ Id.

${ }^{225}$ See, e.g., Sharona Hoffman \& Andy Podgurski, E-Health Hazards: Provider Liability and Electronic Health Record Systems, 24 BERKELEY TECH. L.J. 1523, 1533-52 (2009). 
continued to receive an elevated dose of anticoagulant. Fortunately, the patient survived subsequent emergency open heart surgery. ${ }^{226}$

This offers a robust legal hypothetical. In actions against the healthcare providers, what types of evidence would be referenced in setting the professional standard of care for modern workflows incorporating HIT products (including system choice, training, and transition planning). Similarly, assuming a design defect allegation against the CPOE application seller for, say, failing to include a persistent warning of failure to complete an entry, what design (in particular, human factors) norms would be addressed by expert evidence.

Of course, a limited set of granular norms for the performance of an EMR is set forward in the Certification Standards. ${ }^{227}$ These "criteria establish the required capabilities and specify the related standards and implementation specifications that certified electronic health record (EHR) technology will need to include to, at a minimum, support the achievement of meaningful use Stage 1."228 For example, sub-part B incorporates a large number of detailed external standards and specifications regarding EMR functionality. Similarly, the detailed MU requirements create admittedly minimum standards for providers using EMRs. ${ }^{229}$

As the MU program has progressed and EMR use has grown, an array of quite detailed information about HIT and its use has been published. For example, a comprehensive guide for reducing adverse results arising from EMR use is available from AHRQ. The guide addresses the avoidance of unintended consequences (such as by reviewing skipped or rejected alerts), understanding such consequences (such as by using analytical frameworks), and remediating adverse results (such as by changing processes) ${ }^{230}$ It seems unassailable that such published work will inform the norms applicable to health care providers in their use of HIT. While such norms may influence how courts set standards for those who actually use EMRs, more difficult questions arise with regard to providers who have not implemented them and who face

\footnotetext{
${ }^{226}$ John Halamka, Order Interrupted by Text: Multitasking Mishap, WEB M\&M, Dec. 2011, available at http://webmm.ahrq.gov/case.aspx?caseID=257; for other CPOE errors, see Adelman et al., Understanding and Preventing Wrong-Patient Electronic Orders: A Randomized Controlled Trial, J. Ам. MEd. InFormatics Ass'N 1-6 (June 29, 2012).

${ }^{227}$ Health Information Technology: Initial Set of Standards, Implementation Specifications, and Certification Criteria for Electronic Health Record Technology, 45 C.F.R. $§ 170$ (2010). ${ }^{228} \mathrm{Id}$

${ }^{229}$ Medicare and Medicaid Programs, Electronic Health Record Incentive Program, 42 C.F.R. $\S \S 412,413$, $422, \& 495$ (2012)

${ }^{230}$ Spencer S. Jones et al., Guide to Reducing Unintended Consequences of Electronic Health Records, Agency for HealthCare Res. \& Quality (Aug. 2011), available at http://www.ucguide. org/index.html.
} 
professional negligence allegations, arguing that HIT implementation would have avoided an adverse result. ${ }^{231}$

Whatever the answer is today, a separate question arises when carrots turn to sticks in 2015 and it becomes government policy to penalize providers for failing to make MU of available technologies. At that point, providers likely will find it increasingly difficult to resist the argument that it is malpractice not to have a functioning EMR.

Going forward and assuming eventual Class 3 FDA regulation, ${ }^{232}$ the liability picture will be affected by federal preemption rules, specifically the medical device amendments to the Federal Food, Drug, and Cosmetic Act. ${ }^{233}$ Broad preemption of state products liability claims is granted to products subject to premarket approval. ${ }^{234}$ In contrast, preemption generally does not apply to medical devices that are "substantially equivalent" to existing devices that attract the more limited section $510(\mathrm{k})$ premarket notification process ${ }^{235}$ Products claims based on a manufacturing defect theory alleging seller violation of FDA standards also may survive preemption. ${ }^{236}$ Significantly, The Food and Drug Administration Safety and Innovation Act of 2012 instructs the FDA to create a "strategy and recommendations on an appropriate, risk-based regulatory framework pertaining to health information technology ... that promotes innovation, protects patient safety, and avoids regulatory duplication."237

It is a sad commentary on today's state of EMR design that EMR vendors seem to favor the inclusion of some controversial clauses in their supply contracts. First, they frequently use "gag" clauses that limit health care providers from disclosing product errors or inadequate performance. ${ }^{238} \mathrm{Sec}-$ ond, some contracts include "hold-harmless" clauses requiring health care providers to indemnify EMR manufacturers in case of adverse results. Both types of clauses have been criticized in reports from the American Medical

${ }^{231}$ See generally Howard Melvis, Electronic Medical Records: Liability Is Lurking, AAOS Now, July 2010, available at http://www.aaos.org/news/aaosnow/jul10/managing5.asp.

${ }^{232}$ See supra text accompanying notes 218-223.

${ }^{233} 21$ U.S.C. $\S 360 \mathrm{k}(\mathrm{a})(2006)$.

${ }^{234}$ See, e.g., Riegel v. Medtronic, Inc., 552 U.S. 312 (2008).

${ }^{235}$ See, e.g., Medtronic, Inc. v. Lohr, 518 U.S. 470 (1996).

${ }^{236}$ See Bass v. Stryker Corp., 669 F.3d 501 (5th Cir. 2012).

${ }^{237}$ Food and Drug Administration Safety and Innovation Act of 2012, Pub. L. No. 112-144, § 618, 126 Stat. 993, 1063 (2012).

${ }^{238}$ Bonnie Darves, EHR Vendor Contract Controversy Persists, IHEalthBeat, May 7, 2012, http:// www.ihealthbeat.org/features/2012/ehr-vendor-contract-controversy-persists.aspx?utm_source=feed burner\&utm_medium $=$ feed $\&$ utm_campaign $=$ Feed $\% 3 \mathrm{~A}+$ Ihealthbeat $\% 2 \mathrm{FB}$ usinessAndFinance $+\% 28$ iHB+-+Business+and+Finance\%29\#ixzz1 us_UUIPW3. 
Informatics Association ${ }^{239}$ and the $\mathrm{IoM}^{240}$ as running counter to public policy and hindering safety-improvement. In the words of Koppel and Kreda: "While it is proper that HIT vendors should be held harmless from others' failures, being held responsible for their own errors will bring incentives into balance and enable learned intermediaries to focus on patient care, rather than on coping with product inadequacies or failures."241

Although regulatory and liability models can be slow to evolve and frequently are clumsy in their application, in this instance they may push the EMR vendors towards higher quality and better usability faster than the market or escalating $\mathrm{MU}$ requirements.

\section{CONCLUSION}

Criticism of the MU program seems somewhat churlish; harsh treatment of ONC's thoughtful approach to public policy. After all, the MU program was something of an accident of circumstance. When faced with market failure, it is not the American preference to turn to government. But, in 2009, a financial crisis requiring public works style investment happened upon some pre-drafted legislation from the prior administration ${ }^{242}$ ONC could have made it "easy" on the industry and simply mailed checks to any provider who sent in a facially reasonable request to support an EMR project. Instead, the agency embarked on a far more challenging journey to change the way medicine is practiced. So framed, and with such ambition, MU is less about channeling paper records to electronic platforms and more about moving providers to a new HIT ecosystem.

But critical analysis remains appropriate. The challenge in assessing the progress of the MU program is in finding an appropriate metric. Is the registration of $50 \%$ of physicians and $75 \%$ of hospitals a success or a failure? Do we judge the reinvention of health care by reference to the forwardthinking HIT deployed by HIMSS's overachieving Stage 7 hospitals ${ }^{243}$ or by its almost total absence from small, rural facilities? From another perspective, metrics inherent in the mechanics of MU (registrations, attestations, and the

${ }^{239}$ Kenneth W. Goodman et al., Challenges in Ethics, Safety, Best Practices, and Oversight Regarding HIT Vendors, Their Customers, and Patients: A Report of an AMIA Special Task Force, 18 J. AM. MED. INFORMATICS Ass' N 77, 77-78 (2011), available at http://jamia.bmj.com/content/18/1/77.full.pdf+html.

Inst. Med., Health IT and Patient Safety: Bullding Safer Systems for Better CARE 2 (2011), available at http://www.iom.edu/ /media/Files/Report\%20Files/201 1/Health-IT/ HealthITandPatientSafetyreportbrieffinal_new.pdf.

${ }^{241}$ Ross Koppel \& David Kreda, Health Care Information Technology Vendors' "Hold Harmless" Clause, 301 J.A.M.A. 1276, 1278 (2009).

${ }^{242}$ E.g., Wired for Health Care Quality Act, S. 1693, 110th Cong. (2007).

${ }^{243}$ See HIMSS Analytics Stage 7 Award-Paperless and Proud of It!, HIMSS ANalytics (2012), http:// www.himssanalytics.org/hc_providers/stage7Award.asp. 
like) are perhaps irrelevant if the success or failure of the program is reframed by reference to its impact on the next generation of physicians, the subsidy investment perhaps being viewed as worthwhile for exposing so many medical students and residents to HIT.

Such generous caveats aside, there are several reasons for concern about the program as it reaches its midpoint. Increased deployment and education notwithstanding, the ARRA-sourced subsidy remains the major driver for EMR adoption. ${ }^{244}$ Ezekiel Emanuel reminds us that the MU program was built on an escalating model, whereby "you start with modest requirements to get physicians and hospitals on board and then escalate them to ensure a more robust system." However, as he comments: "People like me worry whether the escalation will really occur." 245 Much of the pushback against Stage 2 described above focuses on some key functionality, such as data sharing and exchange. Like Stage 1 before it, Stage 2 has now been placed on an extended and far more conservative timeline. If the number of providers capable of complying with advanced MU requirements remains modest, the 2015 penalties may begin to look politically untenable. CMS could find itself penalizing poorer and often rural providers that make up a disproportionate part of the safety net. Hardship exemptions from 2015 penalties have been mooted. ${ }^{246}$ A recent KPMG report put the MU program into a broader context: "While some projects have ultimately been successful, more often they have lost momentum after the pilot phase, collapsed under their own complexity, or become irredeemable thanks to spiraling implementation costs." 247 Specifically, the report noted retreats by the governments of The Netherlands and the UK, "reflecting the significant challenges faced by some of the larger, government-led programs." 248

This article has also discussed a performance gap between the stated expectations of the MU architects and the EMRs that are currently installed in most health care facilities. If accurate, the gap helps to explain the inability of too many providers to meet Stage 1 , let alone Stage 2, requirements. It is also consistent with a looming safety problem that almost inevitably will lead to FDA regulation of EMRs.

\footnotetext{
${ }^{244}$ Molly Merrill, Survey Reveals Docs' Perceptions of EHRs as Potential Buyers, Users, HealthCare IT News (Aug. 8, 2011), http://www.healthcareitnews.com/news/survey-reveals-docsperceptions-ehrs-potential-buyers-users.

${ }^{245}$ Emanuel, supra note 94.

${ }^{246}$ Emily Walker, Health IT Break Sought for Docs in Small Practices, MedPAGE Today (May 2, 2012), http://www.medpagetoday.com/PracticeManagement/InformationTechnology/32473 (citing a May 1, 2012, letter from Rep. Renee Ellmers to CMS Acting Administrator Marilyn Tavenner). CMS has suggested a hardship rule in a proposed amendment to the e-prescribing incentives. Id.

${ }^{247}$ KPMG, ACCELERATING INNOvation: THE POWER OF THE CROWd 2 (2012), available at http://www.kpmg. $\mathrm{com} /$ Global/en/IssuesAndInsights/ArticlesPublications/accelerating-innovation/Documents/ehealth${ }^{248}$ Id. mplementation.pdf.
} 
In 2004, President Bush set a 10-year timetable for the introduction of EMRs. Eight years later, ONC Coordinator Mostashari provided this update, stating that, "[i]n 2016, it's going to be the rare to find a doctor without EHRs." ${ }^{249}$ Unfortunately, the data we have today suggest that in 2016, many providers will be without even basic EMR technologies. This group will include ineligible providers, many poorly funded or rural facilities, and a swathe of older physicians who have not switched away from paper and are unlikely to make the EMR leap during their careers. Even narrowing the focus to EMRequipped providers, 2016 is unlikely to demonstrate much sophisticated use of HIT. The percentage of EMRs that are capable of sophisticated data sharing with other HIT modules, such as CDS or interoperability across data interchanges, may continue to be troublingly small. Unless we are very careful (or lucky), the MU program may end up not so much fixing health care, but confirming one of its fundamental problems; a growing discrepancy between high performing, well-funded vertically integrated models or teaching hospitals and the lower quality providers responsible for the care of millions of other Americans.

\footnotetext{
${ }^{249}$ Diana Manos, Mostashari: "Keep Our Eyes on the Prize," HealthCareIT News, Apr. 26, 2012, http://
} www.healthcareitnews.com/news/mostashari-keep-our-eyes-prize. 